\title{
Prevalence of non-aureus staphylococci species causing intramammary infections in Canadian dairy herds
}

\author{
Larissa A. Z. Condas, ${ }^{*} \dagger$ Jeroen De Buck, ${ }^{*} \dagger$ Diego B. Nobrega, ${ }^{\dagger} \dagger$ Domonique A. Carson, ${ }^{*} \dagger$ Sohail Naushad, ${ }^{*} \dagger$ \\ Sarne De Vliegher,‡ Ruth N. Zadoks,§ John R. Middleton,\# Simon Dufour,Il† John P. Kastelic,* \\ and Herman W. Barkema* ${ }^{1}$ \\ *Department of Production Animal Health, Faculty of Veterinary Medicine, University of Calgary, Calgary, Alberta T2N 4N1, Canada \\ †Canadian Bovine Mastitis and Milk Quality Research Network, St-Hyacinthe, Québec J2S 7C6, Canada \\ ¥M-Team and Mastitis and Milk Quality Research Unit, Department of Reproduction, Obstetrics and Herd Health, Faculty of Veterinary Medicine, \\ Ghent University, Salisburylaan 133, 9820 Merelbeke, Belgium \\ §Institute of Biodiversity, Animal Health and Comparative Medicine, College of Medical, Veterinary and Life Sciences, University of Glasgow, \\ Glasgow, G61 1QH, Scotland, United Kingdom \\ \#Department of Veterinary Medicine and Surgery, University of Missouri, Columbia 65211 \\ IDepartment of Pathology and Microbiology, Faculty of Veterinary Medicine, University of Montreal, C. P. 5000, St-Hyacinthe, Québec J2S 7C6, \\ Canada
}

\section{ABSTRACT}

Non-aureus staphylococci (NAS), the microorganisms most frequently isolated from bovine milk worldwide, are a heterogeneous group of numerous species. To establish their importance as a group, the distribution of individual species needs to be determined. In the present study, NAS intramammary infection (IMI) was defined as a milk sample containing $\geq 1,000 \mathrm{cfu} /$ $\mathrm{mL}$ in pure or mixed culture that was obtained from a cohort of cows assembled by the Canadian Bovine Mastitis Research Network. Overall, 6,213 (6.3\%) of 98,233 quarter-milk samples from 5,149 cows and 20,305 udder quarters were associated with an NAS IMI. Of the 6,213 phenotypically identified NAS isolates, 5,509 (89\%) were stored by the Canadian Bovine Mastitis Research Network Mastitis Pathogen Collection and characterized using partial sequencing of the rpo $B$ housekeeping gene, confirming 5,434 isolates as NAS. Prevalence of each NAS species IMI was estimated using Bayesian models, with presence of a specific NAS species as the outcome. Overall quarter-level NAS IMI prevalence was $26 \%$. The most prevalent species causing IMI were Staphylococcus chromogenes (13\%), Staphylococcus simulans (4\%), Staphylococcus haemolyticus (3\%), Staphylococcus xylosus (2\%), and Staphylococcus epidermidis (1\%). The prevalence of NAS IMI as a group was highest in first-parity heifers and was evenly distributed throughout cows in parities $\geq 2$. The IMI prevalence of some species such as $S$. chromogenes, S. simulans, and S. epidermidis differed among parities.

Received December 17, 2016

Accepted March 25, 2017.

${ }^{1}$ Corresponding author: barkema@ucalgary.ca
Overall prevalence of NAS IMI was $35 \%$ at calving, decreased over the next $10 \mathrm{~d}$, and then gradually increased until the end of lactation. The prevalence of $S$. chromogenes, Staphylococcus gallinarum, Staphylococcus cohnii, and Staphylococcus capitis was highest at calving, whereas the prevalence of $S$. chromogenes, $S$. haemolyticus, S. xylosus, and S. cohnii increased during lactation. Although the overall prevalence of NAS IMI was similar across barn types, the prevalence of S. simulans, S. xylosus, S. cohnii, Staphylococcus saprophyticus, S. capitis, and Staphylococcus arlettae IMI was higher in tiestall barns; the prevalence of $S$. epidermidis IMI was lowest; and the prevalence of $S$. chromogenes and Staphylococcus sciuri IMI was highest in beddedpack barns. Staphylococcus simulans, S. epidermidis, S. xylosus, and $S$. cohnii IMI were more prevalent in herds with intermediate to high bulk milk somatic cell count (BMSCC) and S. haemolyticus IMI was more prevalent in herds with high BMSCC, whereas other common NAS species IMI were equally prevalent in all 3 BMSCC categories. Distribution of NAS species IMI differed among the 4 regions of Canada. In conclusion, distribution differed considerably among NAS species IMI; therefore, accurate identification (species level) is essential for studying NAS epidemiology.

Key words: dairy, mastitis, intramammary infection, coagulase-negative staphylococci, prevalence

\section{INTRODUCTION}

Non-aureus staphylococci (NAS) have been considered pathogens of minor importance in dairy production, particularly compared with major udder pathogens such as Staphylococcus aureus, streptococci, and coliforms. Nevertheless, NAS are the bacteria most 
frequently isolated from udder quarters in all recent North American and European subclinical mastitis surveys (Piepers et al., 2007; Pyorala and Taponen, 2009; Sampimon et al., 2009a; Thorberg et al., 2009; De Vliegher et al., 2012; Dufour et al., 2012). Additionally, because NAS IMI moderately increases SCC, lower acceptable limits for bulk milk SCC (BMSCC) have increased the relative importance of NAS IMI (Piepers et al., 2007).

Although the high prevalence of NAS is widely recognized, their importance remains a topic of debate (Oliver and Jayarao, 1997; Piepers et al., 2007; Fox, 2009; Nickerson, 2009; Sampimon et al., 2009a; Schukken et al., 2009). Some authors consider NAS a main cause of subclinical and persistent mastitis (Sampimon et al., 2009a; Fry et al., 2014), whereas others suggest that NAS have a protective effect against major pathogen IMI (Matthews et al., 1990; De Vliegher et al., 2004). Additionally, although milk production was higher in heifers with NAS IMI compared with uninfected heifers (Schukken et al., 2009; Piepers et al., 2010), in other studies no effect on milk production (Tomazi et al., 2015) or decreased milk production associated with NAS IMI (Taponen and Pyörälä, 2009) have also been reported.

Apparently contrasting findings among studies regarding the effect of NAS on udder health and milk production could be the result of regarding the NAS as one group (Woodward et al., 1987, 1988; Matthews et al., 1990). However, NAS are a large and heterogeneous group (Zadoks and Watts, 2009; Vanderhaeghen et al., 2015), and it is known that differences exist among NAS species regarding their interactions with the host and the environment; consequently, they have variable effects on udder health and milk production (Piepers et al., 2009; Vanderhaeghen et al., 2014; Piccart et al., 2016). For example, IMI with Staphylococcus chromogenes, Staphylococcus simulans, and Staphylococcus xylosus have a greater effect on SCC compared with IMI with other species, such as Staphylococcus cohnii and Staphylococcus sciuri (Taponen et al., 2007; Supré et al., 2011; Fry et al., 2014; De Visscher et al., 2016). Some species, such as S. chromogenes and Staphylococcus epidermidis, seem to be host adapted, whereas others, such as Staphylococcus haemolyticus, act as opportunists (Piessens et al., 2011).

Most studies have included staphylococci species with variable responses to the coagulase test, such as Staphylococcus agnetis, in the group of CNS (Taponen et al., 2012). This classification was based on the phenotypic characteristic of $S$. aureus to coagulate plasma, often applied at a time when only $S$. aureus was characterized as pathogenic and the other NAS species were considered minor pathogens (Becker et al., 2014). However, this classification grouped species that are not necessarily phylogenetically related and does not accurately reflect the variability within the genus Staphylococcus (Becker et al., 2014; Naushad et al., 2016). Therefore, because some NAS species can vary in their response to the coagulase test, we prefer and propose to use the name NAS for this group of species.

Geometric mean BMSCC and housing of lactating cows differ by geographical region (Barkema et al., 2015). Based on the National Cohort of Dairy Farms study conducted in Canada during 2007 and 2008, Dufour et al. (2012) reported no difference in prevalence of NAS IMI among tiestall, freestall, and bedded-pack barns when considering NAS as a single group. However, Olde Riekerink et al. (2008) reported a difference between tiestalls and freestalls in incidence of clinical mastitis caused by various NAS species. Perhaps differences in management practices among housing systems affect the prevalence of IMI with specific NAS species.

Within-herd prevalence of IMI with various NAS species is influenced by parity and lactation stage (Sampimon et al., 2009a; De Visscher et al., 2016). Staphylococcus simulans and S. epidermidis are most commonly isolated from multiparous cows (Taponen and Pyörälä, 2009; Mørk et al., 2012), whereas S. chromogenes more frequently causes IMI in heifers. In the latter, the prevalence is usually higher close to calving, but persistency is also reported (Taponen et al., 2007). In that regard, $S$. simulans can persist in the udder for long intervals throughout lactation, whereas prevalence of $S$. chromogenes IMI decreases shortly after calving (Piessens et al., 2011). Comparison of distribution between front and rear quarters provides information about the source of the IMI attributable to a particular species. Although Barkema et al. (1997) isolated NAS more frequently in rear quarters than in front quarters, De Visscher et al. (2016) did not report a species-specific NAS quarter distribution. There are apparently no North American data on parity and DIM distribution of NAS causing IMI in bovine udder quarters.

A large field cohort study was conducted during 2007 and 2008 by the Canadian Bovine Mastitis Research Network (CBMRN). Data and isolates from this prospective study have enabled further investigation of the relevance of NAS species for the dairy industry. The first objective of the current study was to determine the prevalence and distribution of NAS species causing bovine IMI on Canadian dairy farms. The second objective was to evaluate potential associations of speciesspecific NAS IMI with herd characteristics (region, BMSCC, and barn type) as well as cow characteristics (parity, DIM, and quarter location). 


\section{MATERIALS AND METHODS}

\section{Herds and Cows}

Data and samples were collected in the National Cohort of Dairy Farms study conducted in Canada during 2007 and 2008, as described (Reyher et al., 2011). Briefly, the study included 91 farms allocated into 4 regions: Atlantic Canada (represented by Prince Edward Island, New Brunswick, and Nova Scotia), Québec, Ontario, and the Western provinces (represented by Alberta). Eligibility was primarily based on BMSCC and housing system. Farms were randomly selected based on 3 strata of 12 -mo geometric mean average BMSCC and classified as low, intermediate, and high $(<150,000,150,000-300,000$, and $>300,000$ cells $/ \mathrm{mL}$, respectively). Herds enrolled had to match (within 15 percentage points) the proportion of freestall systems of their respective regional freestall percentages. Additionally, each herd comprised at least $80 \%$ lactating Holstein-Friesian cows milked twice a day and participated in a DHI recording system. A total of 91 herds (17 in Alberta, 27 in Ontario, 29 in Québec, and 18 in the Atlantic provinces) were sampled.

Among the 91 herds, $60 \%$ of lactating cows were housed in tiestalls, $33 \%$ were housed in freestalls, and $6 \%$ were housed on a bedded pack. Two herds were excluded from the analysis to determine the effect of barn type on NAS distribution because both had a mixed-barn design. However, most herds in Alberta and the Atlantic provinces were housed in freestalls (12 and 9 herds, respectively), with a few bedded-pack barns, whereas in Ontario and Québec herds most often had tiestalls (20 and 25 herds, respectively) followed by freestall barns (6 and 3 herds, respectively). Average herd size was 85 cows, mean 305-d milk production was $9,781 \mathrm{~kg}$, and production-weighted arithmetic median SCC was 228,000 cells $/ \mathrm{mL}$ (Reyher et al., 2011). A total of $29.5,29.5,19.2,11.3$, and $10.5 \%$ of lactations were from cows in parity $1,2,3,4$, and $\geq 5$, respectively.

\section{Sampling}

Field sampling and corresponding applied techniques have been described (Reyher et al., 2011). Briefly, over a 2-yr interval (2007 and 2008), CBMRN field technicians and producers aseptically collected quarter milk samples and shipped them to the closest CBMRN laboratory. Two schematic samplings of nonclinical mastitis cows were conducted during the $2 \mathrm{yr}$ of field collection, divided into 4 periods (March-May 2007, June-August 2007, January-March 2008, and June-August 2008). The first sampling covered 10 random lactating cows and the 5 most recently calved cows in each herd. For these cows, quarter milk samples were collected at 3-wk intervals in March to May 2007. The sampling scheme was repeated in January to March 2008 and June to August 2008. The second set of samples was collected during June to August 2007. Samples were obtained at weekly intervals from 15 cows per herd 2 to 4 wk before dry-off, at calving, and 2 wk after calving.

\section{Laboratory Analyses}

Bacteriological culture was done on sheep blood agar and MacConkey agar. All plates were incubated at $37^{\circ} \mathrm{C}$ and examined for bacterial growth at 24 and $48 \mathrm{~h}$. Following $48 \mathrm{~h}$ of incubation, colonies were enumerated and species were presumptively identified using recommended phenotype-based bacteriologic procedures (Hogan et al., 2009). Milk samples with growth of $\geq 3$ different microorganisms were considered contaminated (Reyher et al., 2011), whereas of the samples identified as NAS positive (NAS presenting $\geq 10$ phenotypically identical colonies in pure culture) were stored (Reyher et al., 2011).

\section{Definition of IMI}

To be stored in the CBMRN Mastitis Pathogen Culture Collection (MPCC), an NAS isolate had to be retrieved from a milk sample containing $\geq 1,000$ NAS $\mathrm{cfu} / \mathrm{mL}$ of milk in pure culture. Whenever 2 phenotypically different colony types were retrieved (including 2 different NAS), a mixed growth status was attributed to the milk sample, and NAS isolates were not preserved in the MPCC. A quarter was defined as having an NAS IMI using these same criteria.

\section{NAS Isolate Identification}

All NAS isolates were shipped in lyophilized form in vials labeled with individual isolate barcodes to the University of Calgary (Calgary, AB, Canada). Bacteria were resuspended with sterile ultrapure distilled water, plated on 5\% defibrinated sheep blood agar plates, and incubated at $35^{\circ} \mathrm{C}$ for $24 \mathrm{~h}$. Initial screening to confirm that isolates were staphylococci was done using morphology and phenotypic tests (catalase, coagulase, and Gram stain). Subsequent PCR amplification and sequencing with universal primers $27 \mathrm{~F}-1392 \mathrm{R}$ were done to confirm identification of non-NAS isolates previously misclassified during collection (Chakravorty et al., 2007). Extraction of DNA was done as described (Sampimon et al., 2009b). Briefly, a loopful $(1 \mu \mathrm{L})$ of cells was suspended in $20 \mu \mathrm{L}$ of lysis buffer $(0.25 \%$ SDS, $0.05 N \mathrm{NaOH}$ ), heated for $5 \mathrm{~min}$ at $95{ }^{\circ} \mathrm{C}$, and diluted 10 -fold in distilled water. After elimination of 
cell debris by centrifugation, the supernatant was used as a PCR template.

Partial sequencing of the rpoB gene was performed as described (Mellmann et al., 2006). Staphylococcusspecific primer sets used for amplification were staph rpoB_1418F and staph_rpoB_3554R, which resulted in an amplicon of $899 \mathrm{bp}$. Thermal cycling conditions were 5 min at $94^{\circ} \mathrm{C}$ as the first denaturation step, followed by 35 cycles of denaturating at $94^{\circ} \mathrm{C}$ for $45 \mathrm{~s}$, annealing at $52^{\circ} \mathrm{C}$ for $60 \mathrm{~s}$, and extension at $72^{\circ} \mathrm{C}$ for $90 \mathrm{~s}$, with a final extension step at $72^{\circ} \mathrm{C}$ for $10 \mathrm{~min}$. Primers for sequencing were $1418 \mathrm{~F}$ and 1975R (500 bp; Mellmann et al., 2006). Sanger sequencing for all amplicons was performed at University of Calgary Core DNA Services (Calgary, AB, Canada). Pairwise-aligned sequence data were compared with sequence data in GenBank using the nucleotide BLAST algorithm of the National Center for Biotechnology Information (http://blast.ncbi. nlm.nih.gov). The NAS species were identified with $\geq 97 \%$ identity to database sequences, as described (Drancourt and Raoult, 2002; Mellmann et al., 2006), except when the coverage identity was $\leq 50 \%$ or when there was high identity $(\geq 97 \%)$ with 2 species. In these cases, complete rроB gene sequences (full length) were retrieved and searched by BLAST (http://blast.ncbi. nlm.nih.gov) against whole-genome sequences of 450 bovine intramammary NAS isolates, selected from the current study to include all NAS species present in the MPCC and verified by their full $16 \mathrm{~S}$ ribosomal DNA sequences (Naushad et al., 2016).

\section{Statistical Analyses}

Data were analyzed using R (Crawley, 2013), with $P<0.05$ considered significant. Bulk tank SCC categories were determined using the monthly geometric mean BMSCC from the 2-yr duration of the study. Three categories were created: $\leq 150,000,151,000$ to 249,000 , and $\geq 250,000$ cells $/ \mathrm{mL}$. The cut-off for the highest BMSCC category was lower than that for the original categories because the BMSCC of a relatively large number of farms decreased during data collection.

Prevalence Estimation. The prevalence of each NAS species IMI was estimated using a Bayesian latent class approach. Estimated sensitivity of using a single sample to classify a quarter as infected by NAS was $24.2 \%$, with specificity equal to $100 \%$ (Dohoo et al., 2011). Nevertheless, for unknown reasons, some NAS isolates present in $\geq 1,000 \mathrm{cfu} / \mathrm{mL}$ of milk and in pure culture in the original study were not available for identification (i.e., not preserved in the MPCC), likely resulting in underestimation of true IMI prevalence based on traditional frequentist statistical approaches. In this scenario, Bayesian models were expected to be a reliable approach for dealing with imperfections in diagnosis and unpreserved isolates. The latent class model used was similar to a previous one (McInturff et al., 2004) and was as follows:

$$
\begin{gathered}
Y_{\text {collection }} \sim \operatorname{Bernoulli}\left(P_{\text {collection }}\right) \\
P_{\text {collection }}=P_{\text {observed }} \times S e_{\text {collection }}+\left(1-P_{\text {observed }}\right) \\
\times\left(1-S p_{\text {collection }}\right)(\text { measurement error part } 1) \\
P_{\text {observed }}=P_{\text {population }} \times S e_{I M I \text { def }}+\left(1-P_{\text {population }}\right) \\
\times\left(1-S p_{\text {IMI def }}\right)(\text { measurement error part } 2) \\
\text { Logit }\left(P_{\text {population }}\right)=\beta_{0}+\beta_{1} x(\text { response part }),
\end{gathered}
$$

where $Y_{\text {collection }}$ is the NAS species-specific status of an isolate available in the MPCC (e.g., whether it is $S$. chromogenes) and is assumed to followed a Bernoulli distribution with a probability $\left(P_{\text {collection }}\right)$ of having $Y_{\text {collection }}=1$. This probability of observing a given NAS species in the MPCC can be linked to the probability of observing such an IMI among all samples collected during this observational cohort study and identified as NAS IMI with the chosen IMI definition $\left(P_{\text {observed }}\right)$ using the first measurement error part of the model. Thus, this part of the model represented the probability of an isolate that met the inclusion criteria of actually being included (or not) in the MPCC. These probabilities can be linked together using prior knowledge on probability of an isolate of a given species being included in the MPCC $\left(S e_{\text {collection }}\right)$ and probability of an irrelevant isolate being wrongly included in the MPCC $\left(S p_{\text {collection }}\right)$. Then, probability of a sample being observed as positive for a given NAS with the used IMI definition $\left(P_{\text {observed }}\right)$ can be linked to the true population prevalence of that NAS species $\left(P_{\text {population }}\right)$ using the second measurement error part (achieved by including prior knowledge on sensitivity and specificity of the IMI definition chosen; i.e., $S e_{I M I \text { def }}$ and $S p_{\text {IMI def }}$, respectively), where $x$ represents 1 level of a particular variable (i.e., freestall). In that instance, $\beta_{1}$ represents the difference between the logit of the baseline category (i.e., tiestall) and the logit of another category (i.e., freestall). The total number of $\beta$ depends on the variable of interest (i.e., $4 \beta$ are required for estimating the province-specific prevalence). The response part can be used to model the true prevalence of a given NAS species in the population.

Specificity of IMI definition was deemed to be $100 \%$; therefore, only 3 distinct priors using the $\beta$ distribution were used for modeling misclassification of NAS species: sensitivity for using a single sample to define IMI $\left[S e_{I M I}\right.$ def $\left.\sim \beta(66.97,211.80)\right]$, estimated to be approximately $24 \%$; sensitivity for samples that were not ob- 
tained or stored $\left[S e_{\text {collection }} \sim \beta(136.5,17.8)\right]$, estimated to be approximately $89 \%$ (5,509 isolates available out of 6,213 total); and specificity for samples misclassified by our laboratory $\left[S p_{\text {collection }} \sim \beta(56.99,1.5)\right]$, estimated to be approximately $99 \%$ (75 isolates misclassified out of 5,509 evaluated). The specificity prior was used only for estimating prevalence of NAS IMI as a group using all isolates that met the IMI definition on the original data set. After initial evaluation using Bayesian models, this value was assumed to be $100 \%$ and the specificity prior was excluded from final models. Various strategies were tested according to the NAS species. Initially, mixed-effects logit models with herdand cow-specific components for the intercept were fitted for all explanatory variables and for presence or absence of overall NAS IMI and NAS species IMI as a dependent variable in separate models (i.e., 1 model for NAS in general and 1 for each NAS species). Initial analyses considered the complete structure of our data set (repeated measures clustered inside quarter, cow, and herd). Random slopes of DIM at the quarter level introducing autocorrelation (for repeated observation per quarter) were considered but were excluded from final models (lack of convergence). Various explanatory factors were introduced in the models as fixed effects in separate models (e.g., parity, DIM, barn type, province, BTSCC category, and quarter location). For presentation, regression coefficients of interest were converted back to proportions using the invert logit function. For Bayesian models, the Markov chain Monte Carlo method with Gibbs sampling was used with 8 chains in parallel (total of 100,000 iterations using the runjags package in R; Denwood and Plummer, 2016). Visual inspection of the Markov chain, plots of autocorrelation, and effective sample sizes were used to evaluate efficacy. Plots of posterior distribution were visualized, and differences in prevalence estimates between explanatory factors for each species were considered significant when its respective $95 \%$ credible interval did not include zero. For uncommon species, visual inspection of the Markov chains, poor effective sample sizes (defined as $<1,000$ ), and clear autocorrelation of the chains indicated failures in estimation of 1 or more population parameters. In this instance, models were fitted again considering the observations to be independent but introducing the imperfection in sensitivities and specificity as priors. Two important assumptions were that misclassification of NAS species was (1) independent of sample storage and (2) common for all NAS species.

Intraclass Correlation Coefficients. Level of clustering at herd, cow, and quarter (repeated samplings) levels was assessed using intraclass correlation coefficients (ICC), and their respective 95\% credible intervals were estimated for each species using the
Bayesian latent class approach as described previously. Models containing only the intercept and quarter, cow, and herd random effects were fitted and the proportion of variance in each level was estimated considering the variance at the measurement level as described by Dohoo et al. (2010).

Multilevel Multivariable Analysis. The association of quarter-level prevalence of NAS species (S. chromogenes, S. simulans, S.xylosus, and S. haemolyticus) IMI and overall NAS IMI with potential explanatory independent herd-level variables [including barn type, herd size (recorded monthly), and average monthly milk production], the cow-level variable parity (binary: heifers vs. older cows), and the observation-level variables DIM and DIM $^{2}$ as independent variables was estimated using multilevel logistic regression using maximum likelihood and Gaussian quadrature estimation. Models included intercept-specific components for region, herd, cow, and quarter. Two-way interactions were considered based on biological plausibility and possible modification effects (involving barn type, average milk production, and parity) but were excluded from final models. No 3-term interaction was evaluated. Nonsignificant associations (based on likelihood ratio tests) were excluded from final models if no confounding of remaining estimates was observed (change by $15 \%$ or more in the remaining regression coefficients). For predictors with more than 2 categories, overall $P$-values were obtained and adjustments for multiple comparisons were made using the Bonferroni approach. Final models assumed communality of the interpretations of the regression coefficients in terms of other variables presents in the models. For this analysis, an important assumption was that samples identified and not identified did not differ with regard to any association evaluated.

\section{RESULTS}

\section{Data Set}

Overall, 115,294 milk samples were obtained by the CBMRN. Those samples were obtained from 30,398 lactations (range $=1-15$ samples/lactation; mean $=$ 3.7 samples/lactation), 20,571 udder quarters (range $=$ 1-22 samples/quarter; mean $=5.5$ samples/quarter), and 5,157 cows (range $=1-85$ samples $/$ cow; mean $=$ 21.9 samples/cow). From this total, 17,061 samples were contaminated or unavailable for analysis. The remaining 98,233 samples were from 91 herds, 5,149 cows, and 20,305 quarters.

Out of the 98,233 milk samples, a total of 6,213 quarter observations from 91 herds, 2,091 cows, and 3,159 quarters met our NAS IMI definition criteria. A total of 704 isolates were not stored, leaving 5,509 NAS 
isolates for identification. From these NAS isolates, 75 isolates were identified as another bacterial genus or species (32 S. aureus, 19 Corynebacterium spp., 2 Bacillus spp., 3 Brachybacterium spp., 7 Enterococcus spp., 3 Micrococcus spp., 1 Moraxella spp., and 1 yeast) or did not grow from storage media (7 isolates); therefore, 5,434 NAS isolates were available to be included in the analyses. These isolates were obtained from 1,901 cattle and 2,805 quarters.

\section{Distribution of NAS Species IMI}

The 10 most frequently isolated NAS species causing IMI were S. chromogenes, S. simulans, S. xylosus, S. haemolyticus, S. epidermidis, S. cohnii, S. sciuri, Staphylococcus gallinarum, Staphylococcus capitis, and Staphylococcus arlettae. Staphylococcus chromogenes accounted for $49 \%$ of isolates (Table 1).

\section{Clustering}

Quarter-level ICC, measuring correlation in the same quarter for repeated sampling, was high for all NAS species but particularly for $S$. haemolyticus, $S$. chromogenes, and overall NAS (Table 1). At the cow level, ICC ranged from 0.21 to 0.37 (lowest for $S$. cohnii and highest for S. simulans). Notably, for S. cohnii, $S$. sciuri, and S. xylosus, the proportion of variance at the herd level was higher compared with NAS grouped as a single species (Table 1).

\section{Prevalence of NAS IMI}

Overall Prevalence. Quarter-level prevalence of NAS IMI was $25.9 \%$ (Table 1). Except for S. sciuri being less prevalent in left front quarters, prevalence of overall NAS IMI and species-specific IMI was not different among udder quarters (Table 2). Considering parity, quarter-level prevalence of NAS IMI in firstlactation heifers $(35.9 \%)$ was higher than that in cows in parity $2,3,4$, and $\geq 5$ (ranging from $23.2 \%$ for parity $\geq 5$ to $24.2 \%$ for parity 3 ; Figure 1 ). Prevalence of overall NAS IMI was high at calving (35\%), decreased until 10 DIM, and then increased throughout lactation to $40 \%$ in quarters with $\geq 12$ mo of lactation (Figures 2 and 3$)$.

Species-Specific Prevalence. Quarter-level prevalence of S. chromogenes IMI was highest $(23.2 \%)$ in firstlactation heifers [95\% credible region (CR): 18.8-27.4] compared with $9.6 \%$ (95\% CR: 7.7-11.5) in cows in parity $2,9.2 \%$ (95\% CR: $7.5-11.4)$ in cows in parity 3 , 8.2\% (95\% CR: $6.4-10.3$ ) in cows in parity 4 , and $8.0 \%$ (95\% CR: 6.2-10.0) in cows in parity $\geq 5$ (Figure 1).
Prevalence of $S$. simulans IMI was also highest in firstparity cows $(5.9 \%$; 95\% CR: 4.8-7.3) compared with cows in parities 2 (3.5\%; 95\% CR: 2.8-4.4) and 4 (3.4\%; 95\% CR: 2.5-4.5), whereas prevalence of S. epidermidis IMI increased with increasing parity from $0.5 \%(95 \%$ CR: $0.4-0.8)$ in heifers to $2.2 \%$ (95\% CR: $1.5-3.0)$ in cows in parity 4 (Figure 1). Prevalence of $S$. sciuri (0.4\%; 95\% CR: $0.3-0.6)$ and S. gallinarum (0.1\%; $95 \%$ CR: 0.03-0.2) IMI was lowest in first-lactation heifers (Figure 4).

Staphylococcus chromogenes was the most frequently isolated species throughout the entire lactation. Its prevalence was particularly high immediately after calving; it then decreased in prevalence until 5 to 10 DIM and thereafter increased in prevalence again (Figures 2 and 3). Staphylococcus simulans had the next highest prevalence at calving and maintained that prevalence over the first 5 mo of lactation. After mo 4 of lactation, the prevalence of $S$. simulans IMI decreased (Figures 2 and 3). Prevalence of S. haemolyticus and S. gallinarum was relatively high at calving but decreased at 5 to 10 DIM (Figures 2 and 5). As observed for overall NAS IMI prevalence, S. chromogenes, S. xylosus, and $S$. haemolyticus IMI prevalence increased over lactation (Figures 3 and 6).

Prevalence as a Function of Region, Barn Type, and $\boldsymbol{B M S C C}$. Overall NAS IMI prevalence differed among regions; the highest prevalence was in Ontario, and the lowest prevalence was in Quebec and Alberta (Table 3). Similarly, IMI prevalence of most of the 14 most prevalent NAS species except $S$. haemolyticus, S. gallinarum, Staphylococcus warneri, and S. agnetis differed among regions. Prevalence of S. chromogenes IMI was lowest in Québec, whereas the prevalence of $S$. simulans and $S$. capitis IMI was lowest in Alberta, and the prevalence of S. xylosus IMI was lowest in Alberta and the Maritimes (Table 3). Prevalence of S. sciuri was highest in the Maritimes and Alberta, whereas the prevalence of $S$. cohnii and S. arlettae IMI was highest in Ontario. Prevalence of Staphylococcus equorum IMI was highest in Alberta.

Although bedded-pack herds had numerically higher NAS IMI prevalence, the difference was not significant (Table 4). However, IMI prevalence of the 12 most prevalent NAS species except $S$. haemolyticus, S. gallinarum, and $S$. warneri differed between barn types (Table 4). Tiestall herds had higher prevalence of $S$. simulans, S. xylosus, S. cohnii, S. capitis, S. arlettae, and Staphylococcus saprophyticus IMI compared with freestall herds, whereas the prevalence of $S$. simulans, S. xylosus, S. epidermidis, and S. cohnii IMI was higher in cows housed in tiestalls compared with those housed on bedded packs. Prevalence of S. chromogenes, S. epidermidis, and S. sciuri IMI was highest and the preva- 


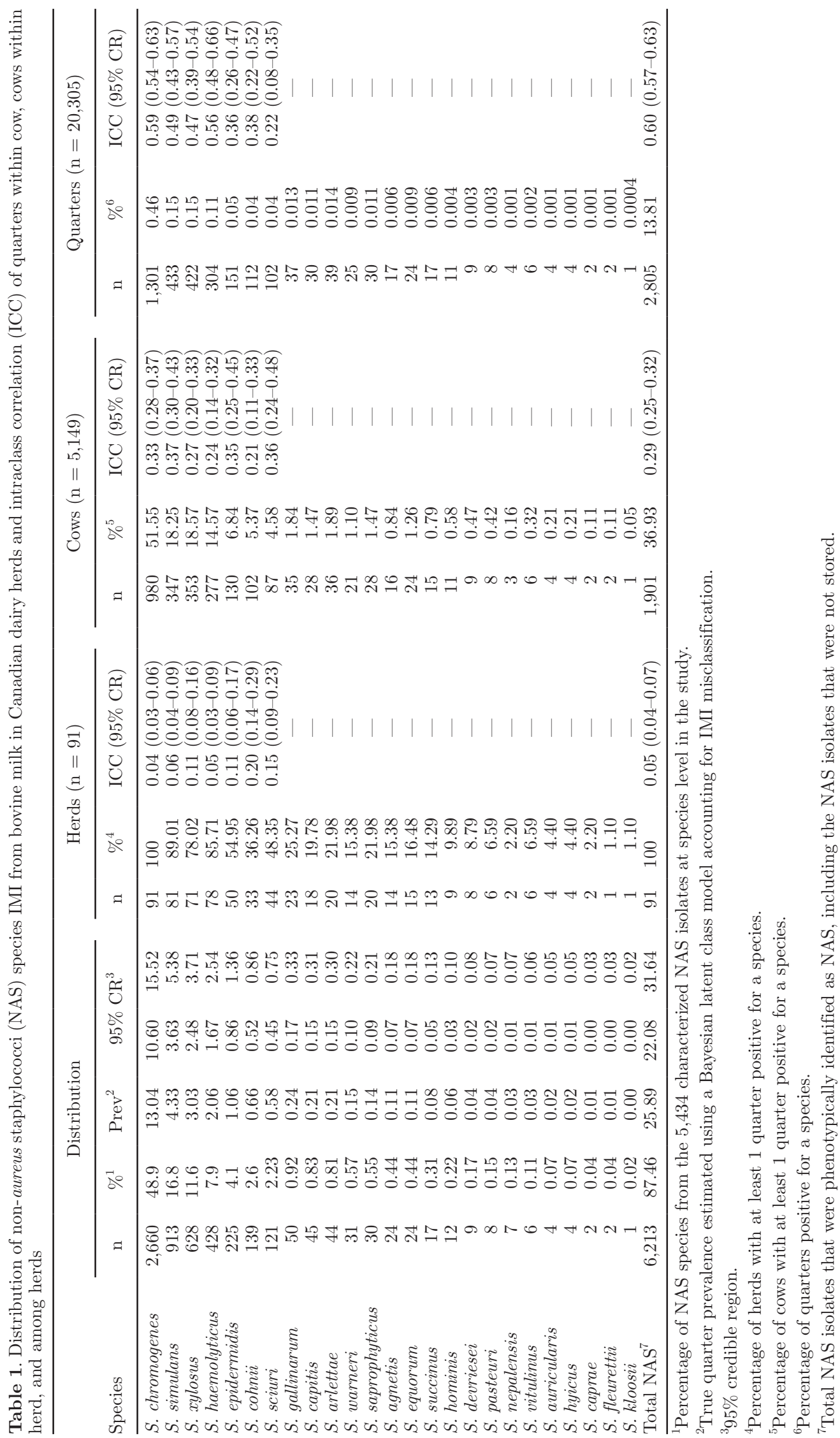




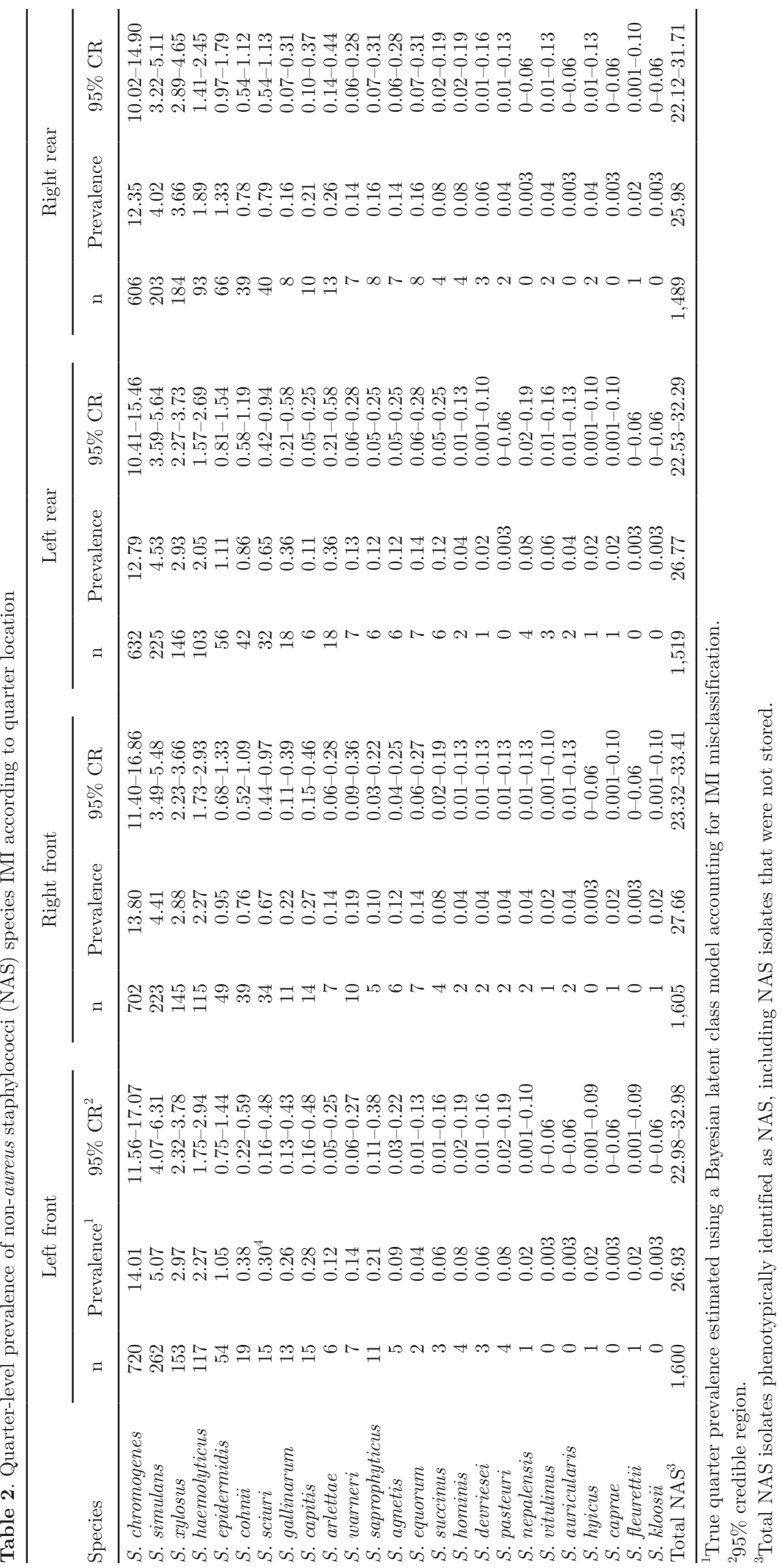




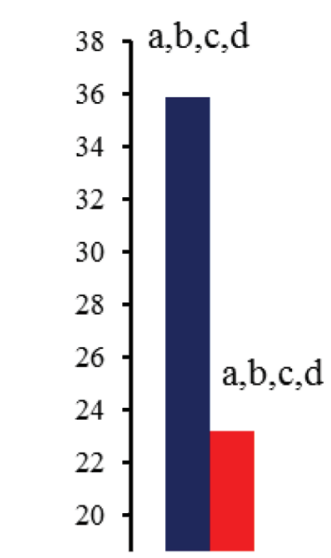

non-aureus staphylococci

$\square$ S. chromogenes

- S. simulans

- S. xylosus

- S. haemolyticus

- S. epidermidis

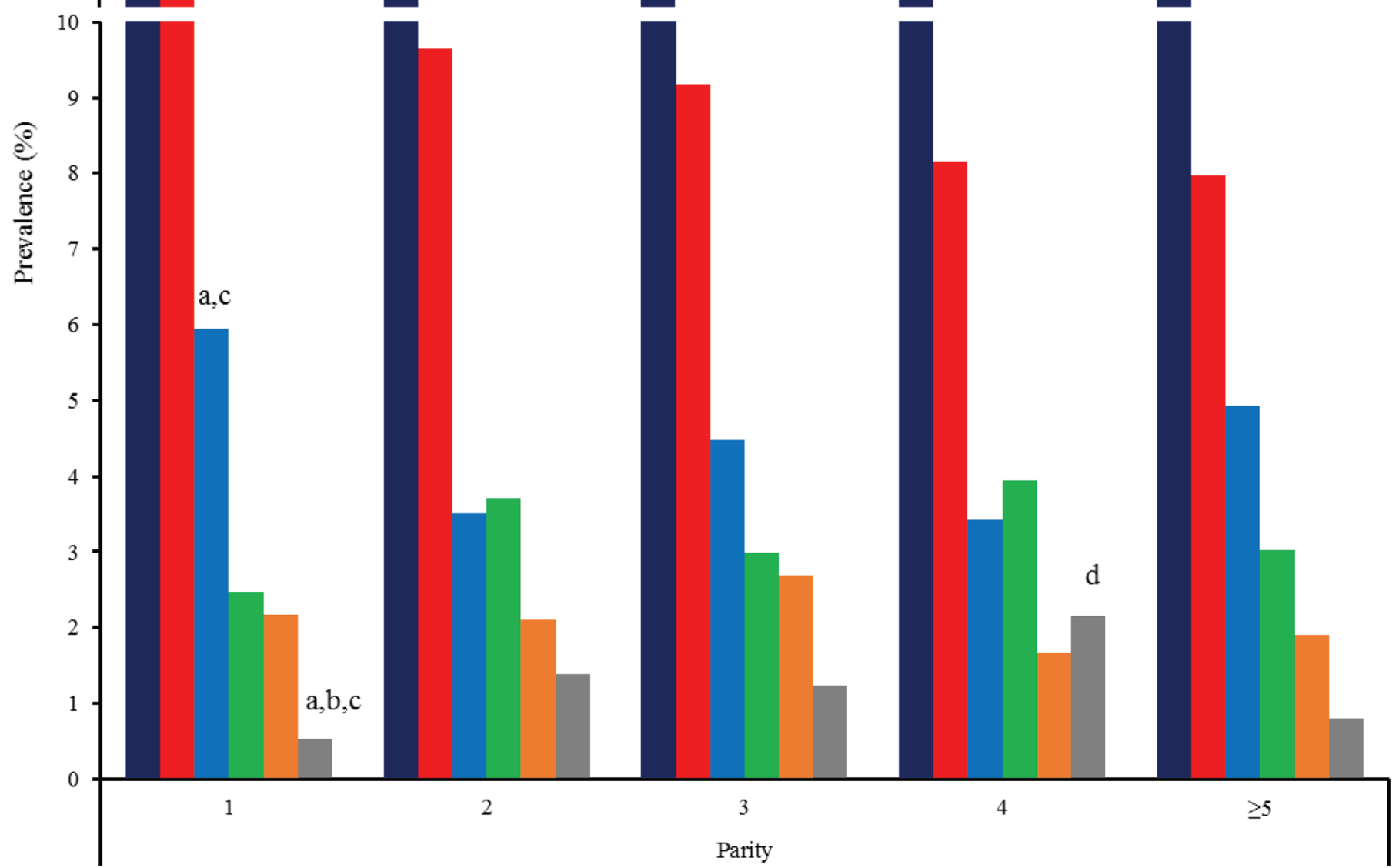

Figure 1. Quarter-level prevalence of IMI with non-aureus staphylococci (NAS) and the 5 most frequently isolated NAS species across parities. True quarter prevalence estimated using a Bayesian latent class model accounting for IMI misclassification. Letters a, b, c, and d indicate different from parity 2 , parity 3 , parity 4 , and parity $\geq 5$, respectively. Color version available online.

lence of S. epidermidis IMI was lowest in cows housed on bedded packs.

Prevalence of NAS IMI decreased numerically with decreasing BMSCC, but the difference was not significant (Table 5). Prevalence of S. simulans, S. epidermidis, and $S$. cohnii IMI was lowest in low BMSCC herds, and prevalence of $S$. haemolyticus IMI was lower in low BMSCC herds than in high BMSCC herds (Table 5). Prevalence of the other NAS species, including $S$. chromogenes, S. xylosus, and S. sciuri, was not different among the 3 BMSCC categories.

\section{Multivariable Analysis}

Mixed-effect logistic regression models were fitted for overall NAS IMI and the IMI prevalence of the 4 most frequently isolated NAS species (Table 6). Associations between species-specific NAS IMI and the independent 
variables were different for the 4 NAS species. The prevalence of overall NAS IMI was associated with DIM and parity, but the direction and shape of the association differed among NAS species. For example, the prevalence of $S$. chromogenes and S. simulans IMI was higher in heifers than in multiparous animals, whereas the prevalence of $S$. xylosus and $S$. haemolyticus IMI was lowest in heifers (Table 6). Also, prevalence of $S$. chromogenes, S. xylosus, and S. haemolyticus IMI increased with increasing DIM.
Freestall herds had a lower prevalence of overall NAS IMI compared with tiestall herds, and low BMSCC herds $(<150,000$ cells $/ \mathrm{mL})$ had a lower prevalence of overall NAS IMI compared with intermediate $(151,000$ $249,000$ cells $/ \mathrm{mL})$ and high $(\geq 250,000$ cells $/ \mathrm{mL})$ BMSCC herds (Table 6). Prevalence of $S$. chromogenes IMI was higher in cows housed on a bedded pack than in those housed in tiestalls and was not different among BMSCC categories. Prevalence of S. xylosus IMI was higher in tiestall herds than in freestall or bedded-pack

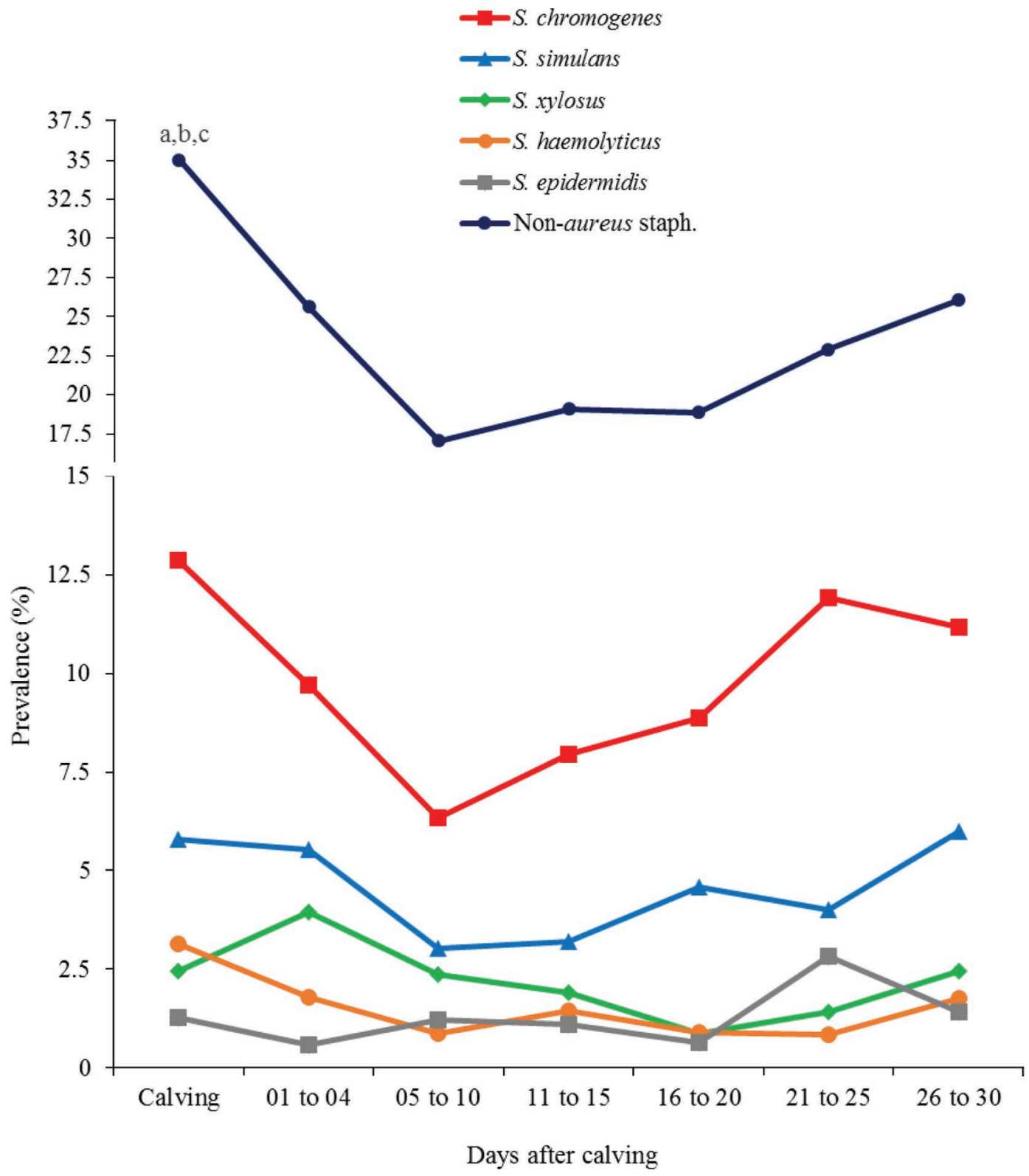

Figure 2. Quarter-level prevalence of IMI with non-aureus staphylococci (NAS) and the 5 most frequently isolated NAS species in the first 30 DIM. True quarter prevalence estimated using a Bayesian latent class model accounting for IMI misclassification. Letters a, b, and c indicate different from 5 to 10 DIM, 11 to 15 DIM, and 16 to 20 DIM, respectively. Color version available online. 


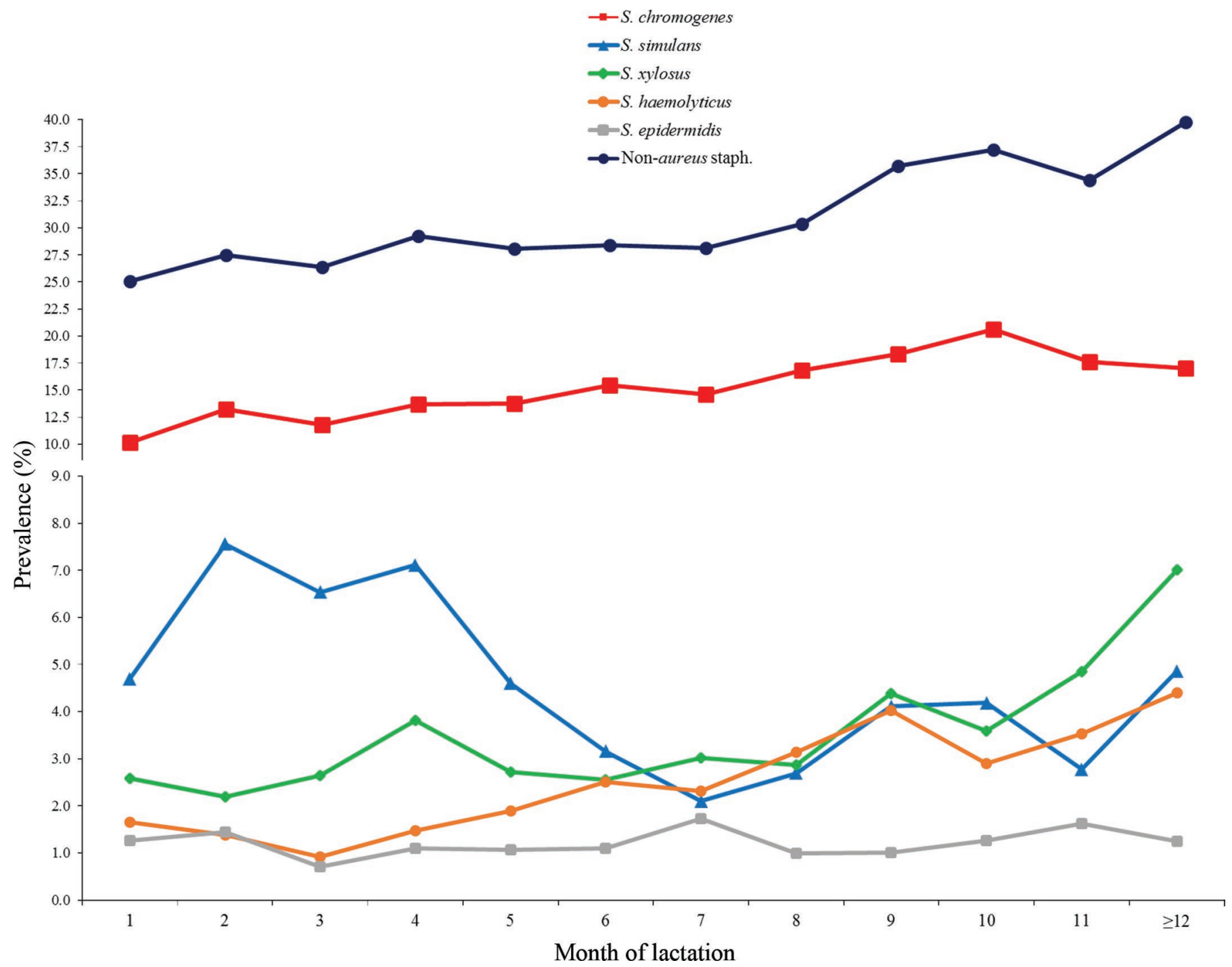

Figure 3. Quarter-level prevalence of IMI with non-aureus staphylococci (NAS) and the 5 most frequently isolated NAS species throughout lactation. True quarter prevalence estimated using a Bayesian latent class model accounting for IMI misclassification. Color version available online.

herds (Table 6). Prevalence of S. simulans IMI was higher in tiestall herds than in freestall herds (odds ratio $=3.0$ ). Barn type and BMSCC category were not associated with prevalence of $S$. haemolyticus IMI, but they remained in the model because of confounding issues.

\section{DISCUSSION}

The data and large number of samples collected in 91 dairy herds provided a unique opportunity to study distribution of NAS IMI across Canada. The herds included closely represented the Canadian commercial dairy farm population regarding distribution of BMSCC and barn type, average milk production, and distribution of parities (Reyher et al., 2011). A total of 25 NAS species were isolated from quarter milk samples. The 5 most prevalent NAS species in this large cohort study were $S$. chromogenes, S. simulans, S. xylosus, S. haemolyticus, and $S$. epidermidis, consistent with findings of the most common NAS species isolated from bovine milk in a study using a subset of the isolates by Fry et al. (2014). The order of frequency, however, differed from that of studies done in other regions, and the prevalence of Staphylococcus hyicus IMI was very low; this was attributed to numerous factors influencing pathogen distribution (e.g., study design, schematic milk sampling, definition of IMI, and not using molecular methods for species identification; Zadoks and Watts, 2009) as well as differences in management conditions and housing 
(Taponen et al., 2006; Taponen et al., 2007; Sampimon et al., 2009a; Thorberg et al., 2009; Piessens et al., 2011; Koop et al., 2012; Piepers et al., 2013).

In our study, NAS species were identified using partial sequencing of the rpo $B$ gene. Identification of a subset of 441 NAS isolates was confirmed using whole-genome sequencing (Naushad et al., 2016). In earlier studies involving NAS species identification, phenotypic methods and methods with low accuracy (e.g., API Staph and Staph-Zym) were used; however, these methods are no longer recommended (Sampimon et al., 2009b; Vanderhaeghen et al., 2015). Sequencing of housekeeping genes and transfer DNA-PCR are the molecular techniques considered the most reliable for identifying NAS species; however, there is a lack of standardization among studies in bovine mastitis (Zadoks et al., 2011; Vanderhaeghen et al., 2015). Whole-genome sequencing is now being used to characterize NAS species and in the future may replace other techniques currently used (Vanderhaeghen et al., 2015). A recent example by Calcutt et al. (2014) mentioned that a proportion of isolates identified as S. hyicus in previous studies would likely now be identified as S. agnetis. Staphylococcus hyicus was reported as one of the most frequently isolated NAS species in earlier studies, not only because of misclassification but also because $S$. chromogenes was considered a subspecies of $S$. hyicus (Zadoks and Watts, 2009). In the current study and others using molecular identification techniques confirmed by whole-genome- sequencing (Naushad et al., 2016), S. hyicus was infrequently isolated. Therefore, differences among studies in methods used to characterize NAS species likely contributed to apparent discrepancies among studies (Vanderhaeghen et al., 2015).

The prevalence of NAS as a group was $26 \%$ at quarter level, similar to some studies conducted in Europe (Chaffer et al., 1999; Pitkälä et al., 2004; Taponen et al., 2007; Supré et al., 2011). By contrast, Schukken et al. (2009) and Gillespie et al. (2009) in the United States, Tenhagen et al. (2006) in Germany, Piessens et al. (2011, 2012) in Belgium, and Sampimon et al. (2009a) in The Netherlands reported a much lower NAS IMI prevalence of 6 to $12 \%$ at the quarter level. However, as mentioned, comparisons of NAS IMI prevalence in the present study with that in previous studies should be done with caution because of variations in definition of IMI and the methodology used to analyze data. In our study, the apparent NAS prevalence (total number of NAS observed out of the total number of eligible milk samples) was 6.3 per 100 samples $(6,213 / 98,233)$, similar to the estimated prevalence reported in studies that ignored misclassification of NAS species. Osterås et al. (2006) reported a very low prevalence of $3.3 \%$ in Norwegian herds, probably the result of a high cut-off for IMI $(>4,000 \mathrm{cfu} / \mathrm{mL})$. In studies that reported an NAS IMI prevalence of 6 to $12 \%$ (Tenhagen et al., 2006; Gillespie et al., 2009; Sampimon et al., 2009a; Schukken et al., 2009; Piessens et al., 2011, 2012), IMI was

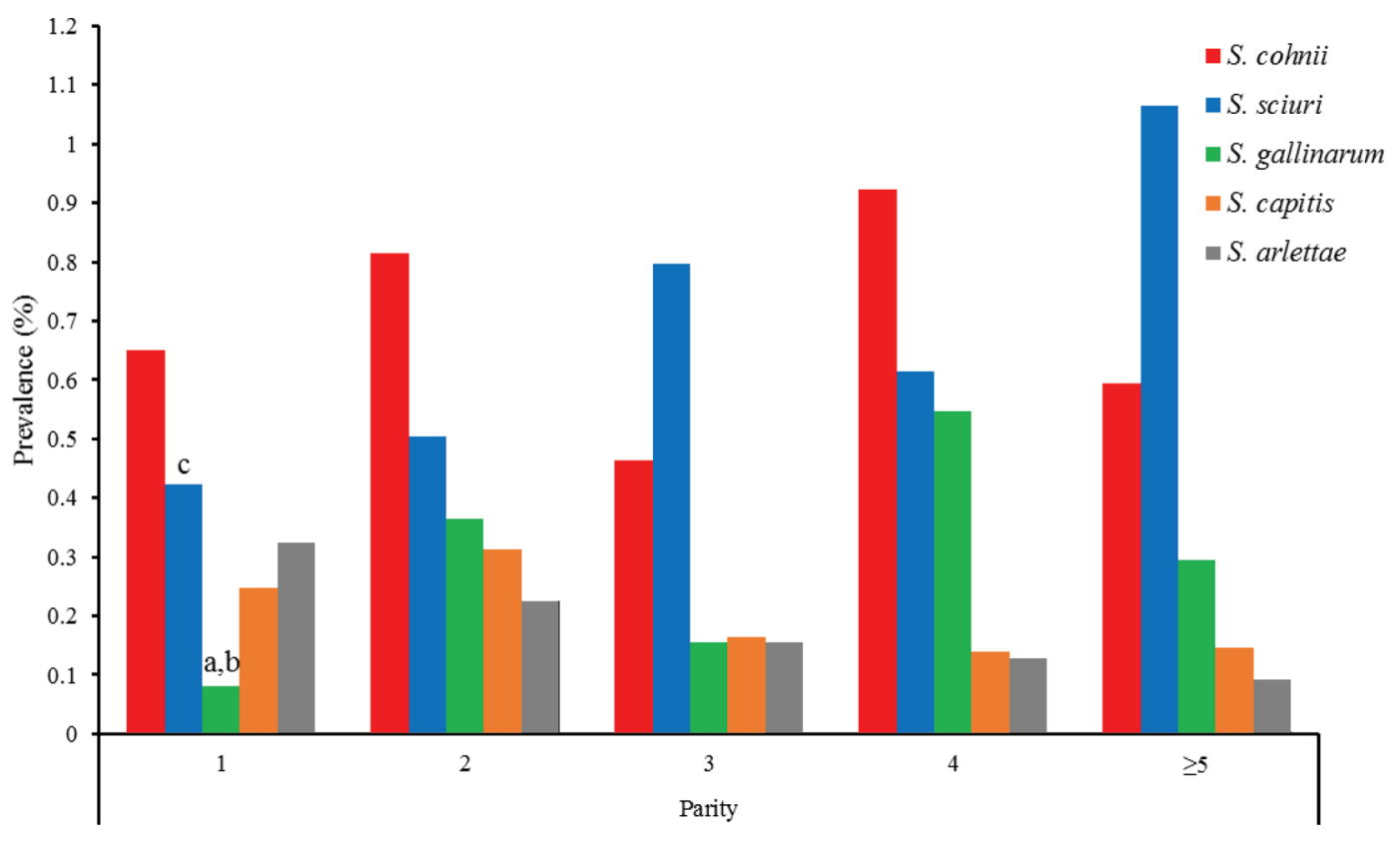

Figure 4. Quarter-level prevalence of the 6th to 10th most frequently isolated species of non-aureus staphylococci IMI across parities. True quarter prevalence estimated using a Bayesian latent class model accounting for IMI misclassification. Letters a, b, and c indicate different from parity 2 , parity 4 , and parity $\geq 5$, respectively. Color version available online. 
defined as quarters with consecutive samplings presenting with a range of colony counts $(>500 \mathrm{cfu} / \mathrm{mL}$ to $>1,000 \mathrm{cfu} / \mathrm{mL}$ ). In the present cohort study, NAS IMI was defined as quarter milk samples with $\geq 10$ colonies in microbiologic culture of $10 \mu \mathrm{L}$ of milk (i.e., $\geq 1,000$ $\mathrm{cfu} / \mathrm{mL}$ ) at a single milk sampling (a method with an estimated sensitivity of $24.4 \%$ for diagnosing an NAS infection based on previously defined criteria; Dohoo et al., 2011). Ignoring test sensitivity in our study dramatically underestimated NAS prevalence. Therefore, the Bayesian latent class approach should be used more consistently when dealing with estimation of prevalence or incidence when data regarding sensitivity and specificity of the method(s) used are readily available.

Clustering within cow was high for most NAS species IMI, particularly when compared with herd-level clustering, possibly the result of a high rate of quarterto-quarter transmission, which indicates a possible contagious characteristic of some NAS species (Barkema et al., 1997). Additionally, relatively high cow-level clustering can also be attributable to unknown factors that confer higher susceptibility for some cows. The relatively high quarter-level clustering indicates persistence of species-specific IMI or reinfection with the same species between samplings (Zadoks et al., 2001; Reyher et al., 2013). Non-aureus staphylococci species might be spread among quarters from direct contact with other teats or indirectly via fomites (e.g., milking machines; Reyher et al., 2013).

In agreement with other reports, heifers had the highest prevalence of overall NAS IMI, and in all studies NAS was the most frequently identified group of bacteria isolated from 22 to $55 \%$ of infected quarters (White et al., 1989; Fox, 2009; De Vliegher et al., 2012; Mørk et al., 2012). The species-specific NAS IMI prevalence differed considerably among parities. Although the 10 most common NAS species in the present study were all present in heifers, S. chromogenes and S. simulans were particularly prevalent in this category. Other reports of common NAS species in heifers include $S$. hyicus (Trinidad et al., 1990), S. simulans (Myllys, 1995), S. chromogenes, S. epidermidis, and S. xylosus (Aar-

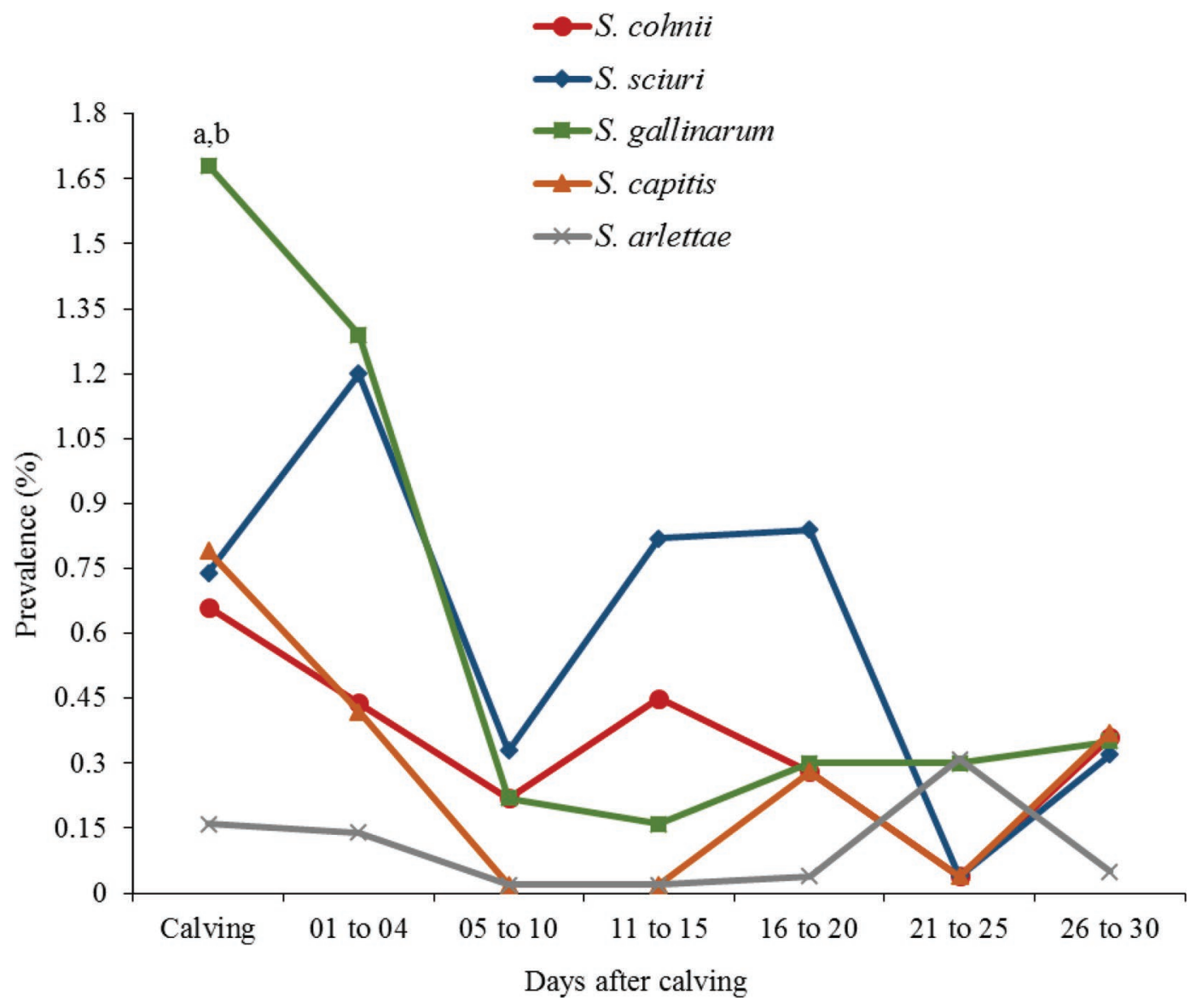

Figure 5. Quarter-level prevalence of the 6th to 10th most frequently isolated species of non-aureus staphylococci IMI in the first 30 DIM. True quarter prevalence estimated using a Bayesian latent class model accounting for IMI misclassification. Letters a and $\mathrm{b}$ indicate different from 5 to $10 \mathrm{~d}$ and 11 to $15 \mathrm{~d}$ after calving, respectively. Color version available online. 
estrup et al., 1995; Myllys, 1995). However, studies in which $S$. hyicus has been identified frequently predate molecular typing (Zadoks and Watts, 2009), whereas this NAS species has been infrequently identified in the molecular era (e.g., Naushad et al., 2016). Staphylococcus chromogenes and $S$. simulans are described as the most udder-adapted NAS species, which may contribute to their high prevalence in heifers (Piepers et al., 2011; De Visscher et al., 2016). Staphylococcus chromogenes is, however, also part of the commensal bovine udder microbiota, although it has the capacity to act as an opportunistic pathogen (De Vliegher et al., 2003; Braem et al., 2012). Equally, S. simulans might act as an udder-adapted opportunist because it was not detected from any source in the milking parlor but was isolated from teat apices (Taponen et al., 2008).

Prevalence of $S$. sciuri and $S$. gallinarum IMI increased with increasing parity, and prevalence of $S$. epidermidis IMI was higher in cows in parities 2 to 4 compared with first-parity heifers. Previous studies did not focus on prevalence of NAS species IMI according to parity, even though Thorberg et al. (2009) reported persistence of IMI by $S$. chromogenes, $S$. simulans, $S$. xylosus, S. epidermidis, and S. cohnii in multiparous cows. These pathogens are ubiquitous in the environment and have the potential to be transmitted cow to cow; therefore, increasing prevalence with age may be related to a combination of persistence and increased susceptibility to infection (Mørk et al., 2012; De Visscher et al., 2014).

Similar to parity, prevalence of IMI with NAS species during lactation differed among species. In several studies, the prevalence of NAS IMI was highest soon after calving, particularly in heifers, and prevalence of NAS IMI subsequently decreased (Matthews et al., 1992; Aarestrup et al., 1995; Piepers et al., 2010). Those studies were similar to the present study with regard to overall NAS IMI, which was attributed to the high prevalence of $S$. chromogenes and to a lesser extent S. simulans. According to Piepers et al. (2010), $72 \%$ of subclinical mastitis cases in fresh heifers were caused by NAS, although 1 wk later those isolates were no longer isolated.

In contrast to a report by Piepers et al. (2010), prevalence of NAS IMI increased over lactation for NAS as a group and for most individual species. The prevalence of IMI with the most common NAS species, S. chromogenes, increased, as did the prevalence of $S$. sciuri (until 4 mo of lactation), S. cohnii, and S. arlettae. According to Taponen et al. (2007), $55 \%$ of $S$. chromogenes and $67 \%$ of S. simulans persisted throughout lactation, and Supré et al. (2011) reported an average duration of 150

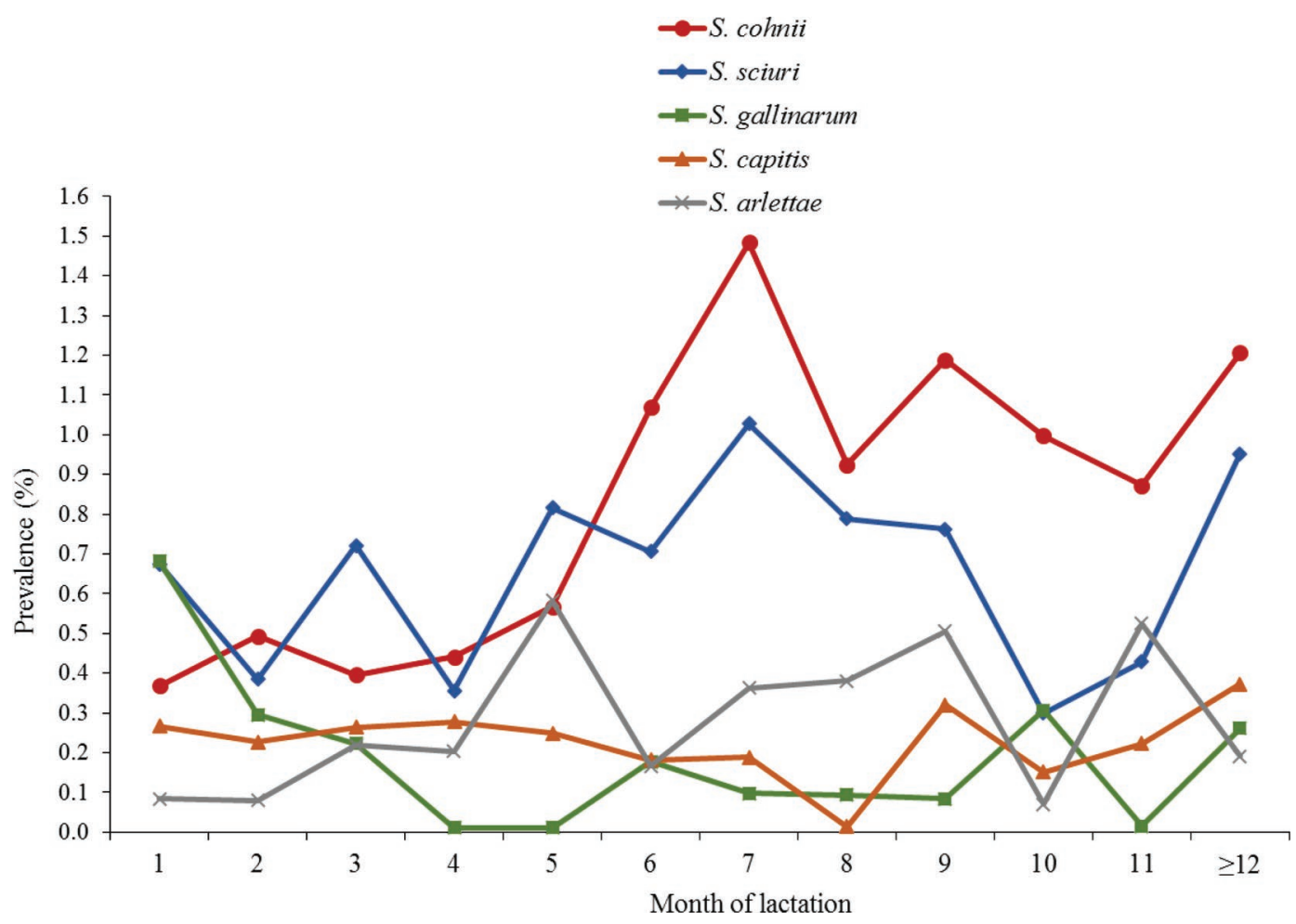

Figure 6. Quarter-level prevalence of the 6th to 10th most frequently isolated species of non-aureus staphylococci IMI throughout lactation. True quarter prevalence estimated using a Bayesian latent class model accounting for IMI misclassification. Color version available online. 


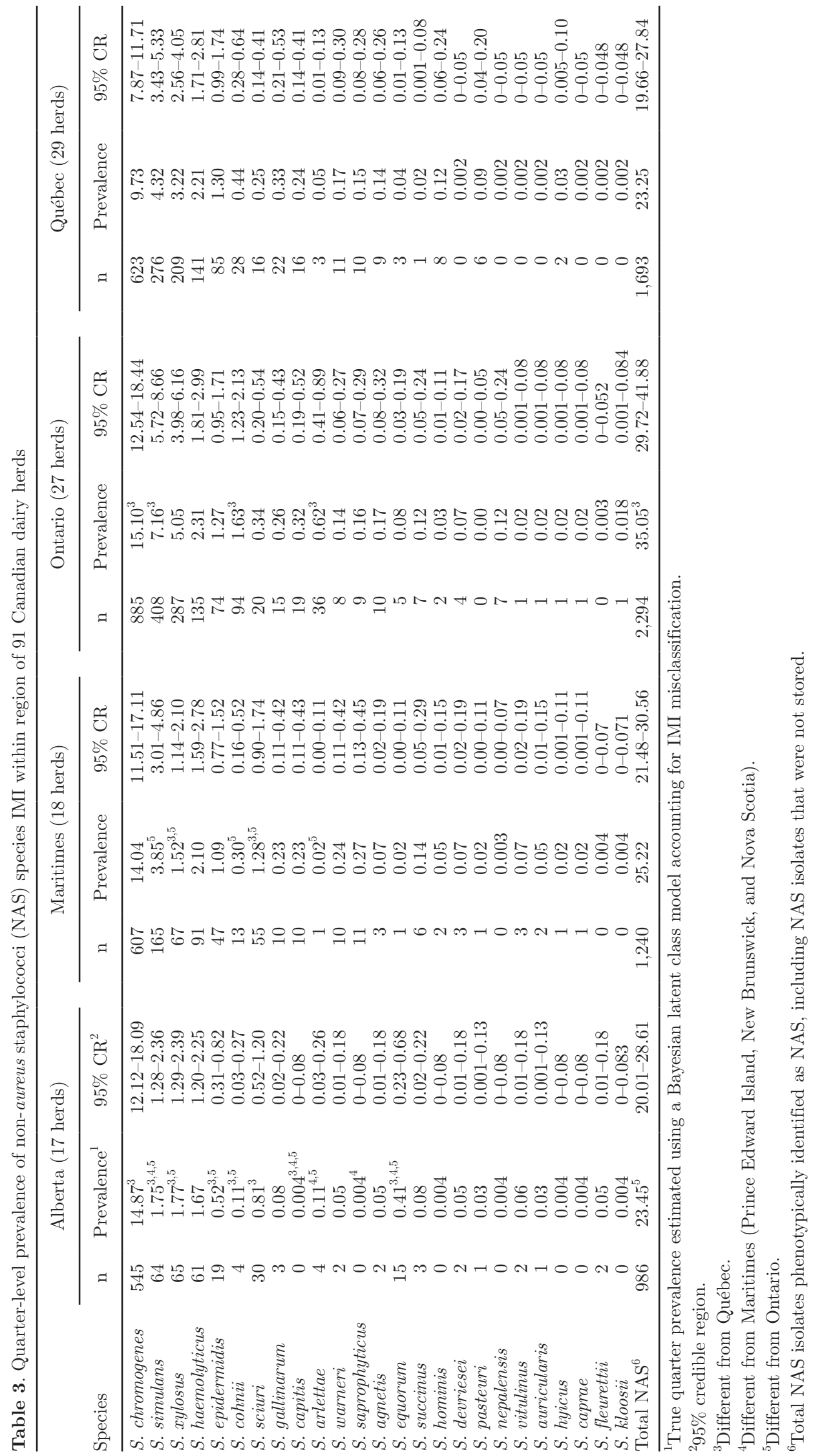


d for S. chromogenes, S. simulans, and S. xylosus IMI. Additionally, perhaps continuous endemic transmission of certain NAS species occurs throughout lactation (Reksen et al., 2012). Further investigation would require a longitudinal study, including strain typing of NAS isolates within cows and quarters.

In most studies, the prevalence of NAS species IMI was highest in herds with a higher BMSCC (Taponen et al., 2006; Taponen et al., 2008; Capurro et al., 2009; Sampimon et al., 2009a; Piessens et al., 2011; Supré et al., 2011). The distribution of NAS species IMI differed among the 3 BMSCC categories in the present study: S. simulans, S. haemolyticus, S. epidermidis, and $S$. cohnii IMI was less prevalent in low BMSCC herds (Table 5), whereas S. chromogenes and S. xylosus IMI was equally prevalent in all 3 BMSCC categories. The proportion of BMSCC associated with NAS IMI has not been frequently evaluated. In a French study, NAS IMI contributed to $18 \%$ of the somatic cells in BMSCC (Rainard et al., 1990). In some large US herds, although the prevalence of NAS IMI increased with increasing BMSCC, the relative effect of NAS IMI on BMSCC decreased with an increasing BMSCC (Schukken et al.,
2009). Recently, Reyher et al. (2013), using the same cohort data reported herein, reported a quadratic relationship between prevalence of NAS IMI and herd SCC that increased proportionally until prevalence reached $20 \%$ and then decreased in SCC after that threshold. Although this association might appear paradoxical, it might be attributable to not only the prevalence of NAS IMI in herds with a higher BMSCC but also the higher prevalence of major pathogen IMI in the same herds (Schukken et al., 2009; ten Napel et al., 2009). In general, IMI with NAS species is associated with a low to moderate increase in quarter milk SCC (Vanderhaeghen et al., 2014; Condas et al., 2017). On farms with BMSCC $>250,000$ cells $/ \mathrm{mL}$, recommended mastitis management practices (e.g., blanket dry cow therapy, postmilking disinfection, treatment of clinical cases, and other hygiene practices) are less common (Dufour et al., 2011). Other practices may also have a role. For example, housing dry cows and pregnant heifers together and contamination of stalls with milk increases the risk of NAS IMI (Sampimon et al., 2009a). Therefore, factors not included in our prevalence models might have had important effects.

Table 4. Quarter-level prevalence of non-aureus staphylococci (NAS) species IMI in 3 barn types

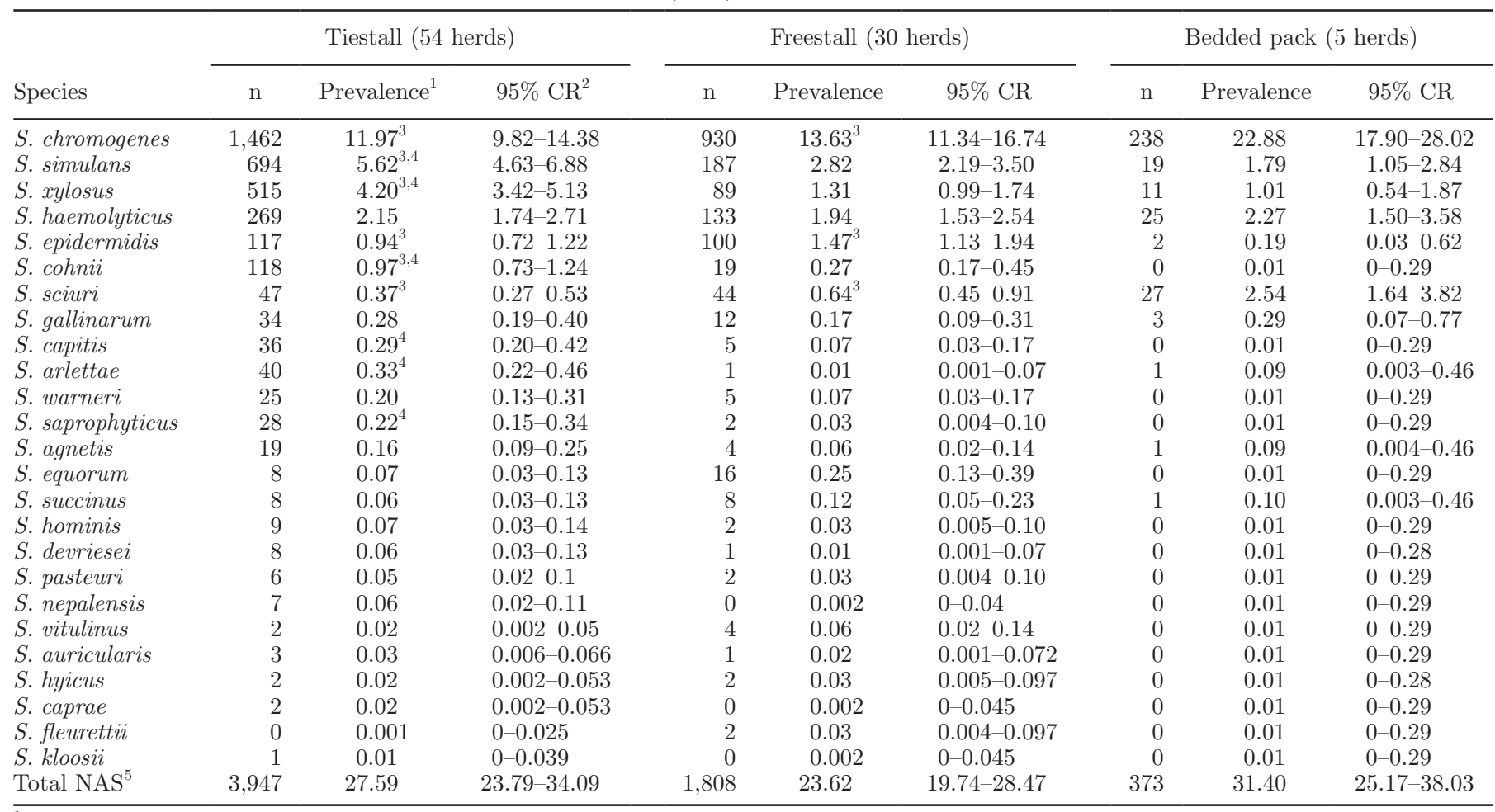

\footnotetext{
${ }^{1}$ True quarter prevalence estimated using a Bayesian latent class model accounting for IMI misclassification. ${ }^{2} 95 \%$ credible region.

${ }^{3}$ Different from bedded pack.

${ }^{4}$ Different from freestalls.

${ }^{5}$ Total NAS isolates phenotypically identified as NAS, including NAS isolates that were not stored.
} 
The distribution of barn types in this study was similar to that in the regions represented (Canadian Dairy Information Centre, 2016) and to a previous Canadian study on clinical mastitis (Olde Riekerink et al., 2006). Farms in Alberta and the Atlantic provinces mostly had freestall and bedded-pack barns, whereas farms in Ontario and particularly Québec had a higher proportion of tiestall barns; variations in BMSCC occurred among the 4 regions. We corrected for these differences in the multivariable analysis, although some differences among the 4 regions remained, likely because of differences in management practices among regions. The distribution of NAS species IMI was different in herds with different housing types (Tables 4 and 6 ). Before molecular species identification of NAS was available, White et al. (1989) reported that S. epidermidis in nonlactating heifers was more frequently isolated from cows housed in freestalls, whereas S. chromogenes and $S$. sciuri were more prevalent in heifers housed in bedded-pack barns than in those housed in freestalls, consistent with our study. Staphylococcus simulans, $S$. xylosus, S. cohnii, S. capitis, S. arlettae, and S. sap- rophyticus IMI were most prevalent in tiestall barns. Different housing systems and management practices within each barn type partially explained the present results. For example, the high prevalence of $S$. xylosus and $S$. simulans IMI could be linked to sawdust, which is mostly used for bedding stalls in tiestall and freestall herds (Matos et al., 1991; Pyörälä and Taponen, 2009). Additionally, De Visscher et al. (2017) reported that environmental aspects such as bedding cleanliness, cow pen grouping, and sources of drinking water were associated with high NAS IMI prevalence. Effects of these management practices on the prevalence of NAS IMI warrant further research.

Various factors evaluated resulted in different associations according to bacterial species. Regardless, unmeasured factors associated with provinces, housing systems, or BMSCC categories could have accounted for part of the residual variance in our analysis. Although other factors may be responsible for the observed effects (i.e., the association in question does not exist once we introduce possible confounders, or the factor in hand was a confounder of a nonevaluated association),

Table 5. Quarter-level prevalence of non-aureus staphylococci (NAS) species IMI according to bulk tank SCC category

\begin{tabular}{|c|c|c|c|c|c|c|c|c|c|}
\hline \multirow[b]{2}{*}{ Species } & \multicolumn{3}{|c|}{$\leq 150,000$ cells $/ \mathrm{mL}$ (13 herds) } & \multicolumn{3}{|c|}{$\begin{array}{c}151,000-249,000 \text { cells } / \mathrm{mL} \\
(47 \text { herds })\end{array}$} & \multicolumn{3}{|c|}{$\geq 250,000$ cells $/ \mathrm{mL}(31$ herds $)$} \\
\hline & $\mathrm{n}$ & Prevalence $^{1}$ & $95 \% \mathrm{CR}^{2}$ & $\mathrm{n}$ & Prevalence & $95 \% \mathrm{CR}$ & $\mathrm{n}$ & Prevalence & $95 \% \mathrm{CR}$ \\
\hline S. chromogenes & 351 & 12.03 & $9.75-14.89$ & 1,392 & 12.55 & $10.36-15.17$ & 917 & 14.24 & $11.86-17.44$ \\
\hline S. simulans & 71 & $2.44^{3,4}$ & $1.79-3.29$ & 570 & 5.15 & $4.21-6.30$ & 272 & 4.13 & $3.34-5.19$ \\
\hline S. xylosus & 71 & 2.42 & $1.79-3.27$ & 359 & 3.21 & $2.61-3.99$ & 198 & 3.15 & $2.47-3.93$ \\
\hline S. haemolyticus & 41 & $1.40^{4}$ & $0.96-1.99$ & 219 & 1.97 & $1.57-2.47$ & 168 & 2.62 & $2.08-3.36$ \\
\hline S. epidermidis & 7 & $0.24^{3,4}$ & $0.10-0.48$ & 124 & 1.10 & $0.85-1.44$ & 94 & 1.45 & $1.11-1.94$ \\
\hline S. cohnii & 6 & $0.21^{3,4}$ & $0.08-0.44$ & 88 & 0.78 & $0.59-1.04$ & 45 & 0.70 & $0.49-1.00$ \\
\hline S. sciuri & 18 & 0.62 & $0.37-1.00$ & 72 & 0.64 & $0.48-0.87$ & 31 & 0.49 & $0.32-0.72$ \\
\hline S. gallinarum & 7 & 0.24 & $0.10-0.49$ & 27 & 0.25 & $0.16-0.36$ & 16 & 0.25 & $0.14-0.41$ \\
\hline S. capitis & 4 & 0.14 & $0.04-0.33$ & 28 & 0.25 & $0.16-0.38$ & 13 & 0.20 & $0.11-0.35$ \\
\hline S. arlettae & 1 & 0.03 & $0.002-0.17$ & 26 & 0.23 & $0.15-0.36$ & 17 & 0.26 & $0.15-0.43$ \\
\hline S. warneri & 7 & 0.24 & $0.10-0.49$ & 8 & 0.07 & $0.03-0.14$ & 16 & 0.25 & $0.14-0.41$ \\
\hline S. saprophyticus & 4 & 0.14 & $0.04-0.33$ & 18 & 0.16 & $0.09-0.26$ & 8 & 0.13 & $0.06-0.25$ \\
\hline S. agnetis & 1 & 0.03 & $0.001-0.17$ & 16 & 0.14 & $0.08-0.24$ & 7 & 0.11 & $0.05-0.22$ \\
\hline S. equorum & 5 & 0.17 & $0.06-0.38$ & 14 & 0.13 & $0.07-0.21$ & 5 & 0.08 & $0.03-0.18$ \\
\hline S. succinus & 4 & 0.14 & $0.04-0.33$ & 7 & 0.06 & $0.03-0.13$ & 6 & 0.10 & $0.04-0.20$ \\
\hline S. hominis & 1 & 0.03 & $0.001-0.17$ & 6 & 0.05 & $0.02-0.11$ & 5 & 0.07 & $0.02-0.15$ \\
\hline S. devriesei & 5 & 0.18 & $0.06-0.39$ & 2 & 0.02 & $0.003-0.06$ & 2 & 0.03 & $0.005-0.10$ \\
\hline S. pasteuri & 1 & 0.04 & $0.001-0.17$ & 4 & 0.04 & $0.01-0.09$ & 3 & 0.05 & $0.01-0.13$ \\
\hline S. nepalensis & 0 & 0.005 & $0-0.11$ & 7 & 0.06 & $0.03-0.13$ & 0 & 0.002 & $0-0.05$ \\
\hline S. vitulinus & 0 & 0.005 & $0-0.11$ & 4 & 0.04 & $0.01-0.09$ & 2 & 0.03 & $0.005-0.10$ \\
\hline S. auricularis & 2 & 0.07 & $0.01-0.23$ & 1 & 0.01 & $0-0.04$ & 1 & 0.02 & $0.001-0.08$ \\
\hline S. hyicus & 1 & 0.03 & $0.001-0.17$ & 1 & 0.01 & $0-0.04$ & 2 & 0.03 & $0.004-0.10$ \\
\hline S. caprae & 0 & 0.01 & $0-0.11$ & 2 & 0.02 & $0.003-0.06$ & 0 & 0.002 & $0-0.05$ \\
\hline S. fleurettii & 2 & 0.08 & $0.01-0.23$ & 0 & 0.001 & $0-0.03$ & 0 & 0.002 & $0-0.05$ \\
\hline S. kloosii & 0 & 0.01 & $0-0.11$ & 1 & 0.01 & 0-0.04 & 0 & 0.002 & $0-0.05$ \\
\hline Total NAS ${ }^{5}$ & 694 & 21.08 & $17.37-25.61$ & 3,433 & 27.18 & $22.66-32.70$ & 2,086 & 28.40 & $23.98-34.60$ \\
\hline
\end{tabular}

\footnotetext{
${ }^{1}$ True quarter prevalence estimated using a Bayesian latent class model accounting for IMI misclassification.

${ }^{2} 95 \%$ credible region.

${ }^{3}$ Different from 151,000 to 249,000 cells $/ \mathrm{mL}$.

${ }^{4}$ Different from $\geq 250,000$ cells $/ \mathrm{mL}$

${ }^{5}$ Total NAS isolates phenotypically identified as NAS, including NAS isolates that were not stored.
} 
NON-AUREUS STAPHYLOCOCCI IN MILK

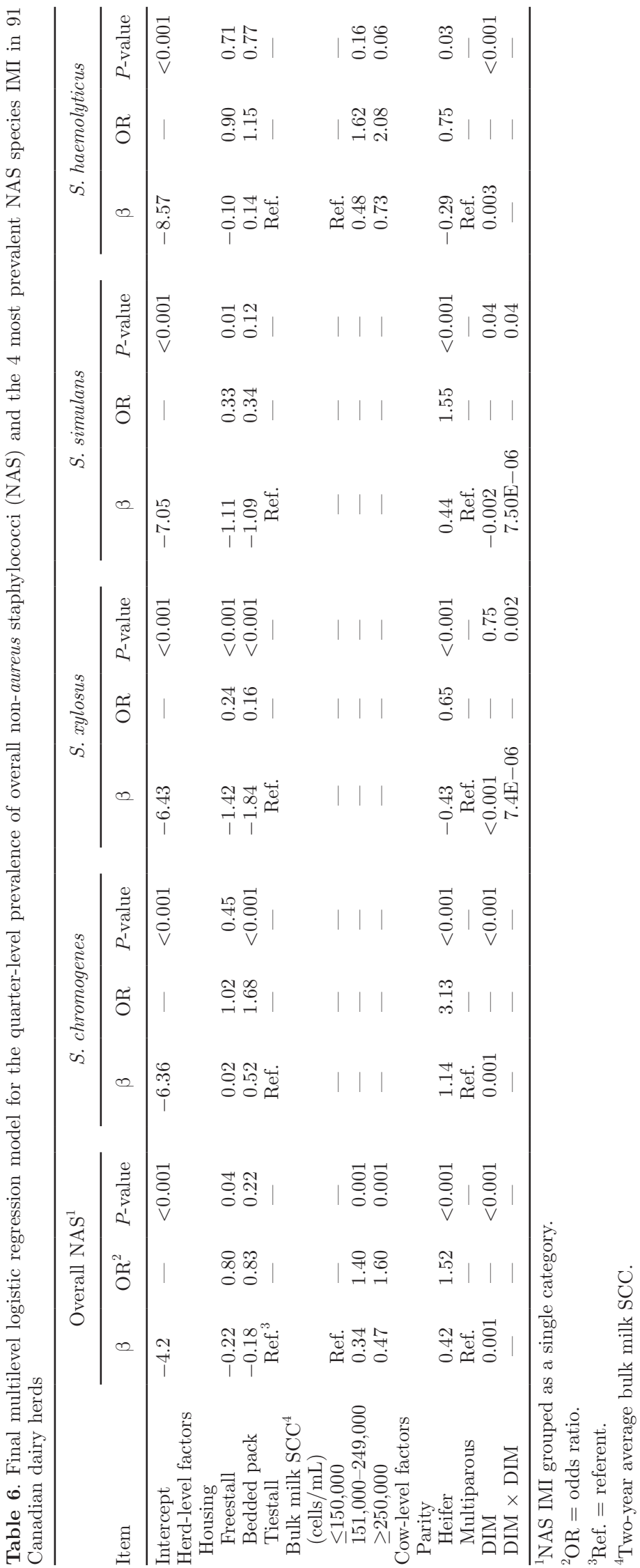


the present study represented a first step in identifying specific risk factors for each NAS species.

When evaluating results for samples from bedded-pack herds, any associations should be evaluated carefully because of the low number of herds under this housing system in the present study. Whenever an interaction involving housing system was present, stratification of bedded-pack herds into smaller categories may reflect an individual herd factor as deemed responsible for the result (or absence of significant result). Further studies are needed to evaluate the prevalence of various NAS species in bedded-pack herds.

\section{CONCLUSIONS}

This large data set facilitated determination of the disparate association of quarters infected by speciesspecific NAS as predictors at herd and cow levels when compared with NAS as an overall pathogen and demonstrated clear differences between species. Therefore, each species should be evaluated independently. Quarter-level prevalence of NAS IMI as a group was $26 \%$. Consistent with other studies, S. chromogenes was the most prevalent species; however, order of prevalence of S. simulans, S. xylosus, S. epidermidis, and S. haemolyticus IMI differed from other countries. Prevalence of IMI with most NAS species was relatively high at calving, particularly in heifers. Prevalence thereafter decreased for a short interval but increased again during lactation. From a herd perspective, management related to different barn types, and BMSCC affected NAS species IMI distribution and influenced distribution among regions.

\section{ACKNOWLEDGMENTS}

This work was partially funded through the Natural Sciences and Engineering Research Council of Canada (NSERC) Industrial Research Chair in Infectious Diseases of Dairy Cattle. This project was also part of the Canadian Bovine Mastitis and Milk Quality Research Network program, funded by Dairy Farmers of Canada and Agriculture and Agri-Food Canada through the Dairy Research Cluster 2 Program. Three of the authors (DBN, DAC, and SN) were supported by an NSERCCREATE in milk quality scholarship. The authors thank all dairy producers, animal health technicians, and Canadian Bovine Mastitis Research Network regional coordinators (Trevor DeVries, University of Guelph, ON, Canada; Jean-Philippe Roy and Luc Des Côteaux, University of Montreal, QC, Canada; Kristen Reyher, University of Prince Edward Island, PE, Canada; and Herman Barkema, University of Calgary, AB, Canada) who participated in data collection. Bacterial isolates were furnished by the Canadian Bovine Mastitis and Milk Quality Research Network (Saint-Hyacinthe, QC, Canada). The Canadian Bovine Mastitis Research Network pathogen and data collections were financed by the Natural Sciences and Engineering Research Council of Canada (Ottawa, ON, Canada), Alberta Milk (Edmonton, AB, Canada), Dairy Farmers of New Brunswick (Sussex, NB, Canada), Dairy Farmers of Nova Scotia (Lower Truro, NS, Canada), Dairy Farmers of Ontario (Mississauga, ON, Canada), Dairy Farmers of Prince Edward Island (Charlottetown, PE, Canada), Novalait Inc. (Québec City, QC, Canada), Dairy Farmers of Canada (Ottawa, ON, Canada), Canadian Dairy Network (Guelph, ON, Canada), Agriculture and AgriFood Canada (Ottawa, ON, Canada), Public Health Agency of Canada (Ottawa, ON, Canada), Technology PEI Inc. (Charlottetown, PE, Canada), Université de Montréal (Montréal, QC, Canada), and University of Prince Edward Island (Charlottetown, PE, Canada) through the Canadian Bovine Mastitis and Milk Quality Research Network.

\section{REFERENCES}

Aarestrup, F. M., H. C. Wegener, V. T. Rosdahl, and N. E. Jensen. 1995. Staphylococcal and other bacterial species associated with intramammary infections in Danish dairy herds. Acta Vet. Scand. $36: 475-487$.

Barkema, H. W., Y. H. Schukken, T. J. Lam, D. T. Galligan, M. L. Beiboer, and A. Brand. 1997. Estimation of interdependence among quarters of the bovine udder with subclinical mastitis and implications for analysis. J. Dairy Sci. 80:1592-1599.

Barkema, H. W., M. A. G. Von Keyserlingk, J. P. Kastelic, T. J. G. M. Lam, C. Luby, J. P. Roy, S. J. LeBlanc, G. P. Keefe, and D. F. Kelton. 2015. Invited review: Changes in the dairy industry affecting dairy health and welfare. J. Dairy Sci. 98:7426-7445.

Becker, K., C. Heilmann, and G. Peters. 2014. Coagulase-negative staphylococci. Clin. Microbiol. Rev. 27:870-926.

Braem, G., S. De Vliegher, B. Verbist, M. Heyndrickx, F. Leroy, and L. De Vuyst. 2012. Culture-independent exploration of the teat apex microbiota of dairy cows reveals a wide bacterial species diversity. Vet. Microbiol. 157:383-390.

Calcutt, M. J., M. F. Foecking, P. R. Fry, H.-Y. Hsieh, J. Perry, G. C. Stewart, D. T. Scholl, S. Messier, and J. R. Middleton. 2014. Draft genome sequence of bovine mastitis isolate Staphylococcus agnetis CBMRN 20813338. Genome Announc. 2:e00883-14.

Canadian Dairy Information Centre. 2016. Dairy barns by type in Canada. Accessed December 17, 2016. http://www.dairyinfo. gc.ca/index_e.php?s1=dff-fcil\&s2=farm-ferme\&s3=db-el.

Capurro, A., K. Artursson, K. P. Waller, B. Bengtsson, H. EricssonUnnerstad, and A. Aspán. 2009. Comparison of a commercialized phenotyping system, antimicrobial susceptibility testing, and tuf gene sequence-based genotyping for species-level identification of coagulase-negative staphylococci isolated from cases of bovine mastitis. Vet. Microbiol. 134:327-333.

Chaffer, M., G. Leitner, M. Winkler, A. Glickman, O. Krifucks, E. Ezra, and A. Saran. 1999. Coagulase-negative staphylococci and mammary gland infections in cows. Zentralbl. Veterinarmed. B. 46:707-712.

Chakravorty, S., D. Helb, M. Burday, N. Connell, and D. Alland. 2007. A detailed analysis of $16 S$ ribosomal $R N A$ gene segments for the diagnosis of pathogenic bacteria. J. Microbiol. Methods 69:330-339.

Condas, L., J. De Buck, D. B. Nobrega, D. A. Carson, J.-P. Roy, G. P. Keefe, T. J. DeVries, J. R. Middleton, S. Dufour, and H. 
W. Barkema. 2017. Distribution of non-aureus staphylococci species in quarters with low and high somatic cell count, and clinical mastitis. J. Dairy Sci. 100:5613-5627. https://doi.org/10.3168/ jds.2016-12479.

Crawley, M. J. 2013. The R Book. 2nd ed. Wiley, Chichester, United Kingdom.

De Visscher, A., S. Piepers, F. Haesebrouck, and S. De Vliegher. 2016. Intramammary infection with coagulase-negative staphylococci at parturition: Species-specific prevalence, risk factors, and effect on udder health. J. Dairy Sci. 99:6457-6469.

De Visscher, A., S. Piepers, F. Haesebrouck, K. Supré, and S. De Vliegher. 2017. Coagulase-negative Staphylococcus species in bulk milk: Prevalence, distribution, and associated subgroup- and species-specific risk factors. J. Dairy Sci. 100:629-642.

De Visscher, A., K. Supré, F. Haesebrouck, R. N. Zadoks, V. Piessens, E. Van Coillie, S. Piepers, and S. De Vliegher. 2014. Further evidence for the existence of environmental and host-associated species of coagulase-negative staphylococci in dairy cattle. Vet. Microbiol. 172:466-474.

De Vliegher, S., L. K. Fox, S. Piepers, S. McDougall, and H. W. Barkema. 2012. Invited review: Mastitis in dairy heifers: Nature of the disease, potential impact, prevention, and control. J. Dairy Sci. 95:1025-1040.

De Vliegher, S., H. Laevens, G. Opsomer, J. L. M. Leroy, H. W. Barkema, and A. de Kruif. 2003. Prepartum teat apex colonization with Staphylococcus chromogenes in dairy heifers is associated with low somatic cell count in early lactation. Vet. Microbiol. 92:245-252.

De Vliegher, S., G. Opsomer, A. Vanrolleghem, L. A. Devriese, O. C. Sampimon, J. Sol, H. W. Barkema, F. Haesebrouck, and A. de Kruif. 2004. In vitro growth inhibition of major mastitis pathogens by Staphylococcus chromogenes originating from teat apices of dairy heifers. Vet. Microbiol. 101:215-221.

Denwood, M., and M. Plummer. 2016. Runjags: An R package providing interface utilities, model templates, parallel computing methods and additional distributions for MCMC models in JAGS. J. Stat. Softw. 71:1-25.

Dohoo, I. R., S. W. Martin, and H. Stryhn. 2010. Veterinary Epidemiologic Research. M. S. McPike, ed. Atlantic Veterinary College, Charlottetown, PE, Canada.

Dohoo, I. R., J. Smith, S. Andersen, D. F. Kelton, and S. Godden. 2011. Diagnosing intramammary infections: Evaluation of definitions based on a single milk sample. J. Dairy Sci. 94:250-261.

Drancourt, M., and D. Raoult. 2002. rpoB gene sequence-based identification of Staphylococcus species. J. Clin. Microbiol. 40:1333-1338.

Dufour, S., I. R. Dohoo, H. W. Barkema, L. Descoteaux, T. J. Devries, K. K. Reyher, J. P. Roy, and D. T. Scholl. 2012. Epidemiology of coagulase-negative staphylococci intramammary infection in dairy cattle and the effect of bacteriological culture misclassification. J. Dairy Sci. 95:3110-3124.

Dufour, S., A. Fréchette, H. W. Barkema, A. Mussell, and D. T. Scholl. 2011. Invited review: Effect of udder health management practices on herd somatic cell count. J. Dairy Sci. 94:563-579.

Fox, L. K. 2009. Prevalence, incidence and risk factors of heifer mastitis. Vet. Microbiol. 134:82-88.

Fry, P. R., J. R. Middleton, S. Dufour, J. Perry, D. Scholl, and I. Dohoo. 2014. Association of coagulase-negative staphylococcal species, mammary quarter milk somatic cell count, and persistence of intramammary infection in dairy cattle. J. Dairy Sci. 97:4876-4885.

Gillespie, B. E., S. I. Headrick, S. Boonyayatra, and S. P. Oliver. 2009. Prevalence and persistence of coagulase-negative Staphylococcus species in three dairy research herds. Vet. Microbiol. 134:65-72.

Hogan, J. S., R. N. Gonzales, R. J. Harmon, S. P. Nickerson, J. W. Oliver, J. W. Pankey, and K. L. Smith. 2009. Laboratory Handbook on Bovine Mastitis. National Mastitis Council, Madison, WI.

Koop, G., S. De Vliegher, A. De Visscher, K. Supré, F. Haesebrouck, M. Nielen, and T. van Werven. 2012. Differences between coagulase-negative Staphylococcus species in persistence and in effect on somatic cell count and milk yield in dairy goats. J. Dairy Sci. 95:5075-5084.
Matos, J. S., D. G. White, R. J. Harmon, and B. E. Langlois. 1991. Isolation of Staphylococcus aureus from sites other than the lactating mammary gland. J. Dairy Sci. 74:1544-1549.

Matthews, K. R., R. J. Harmon, and B. E. Langlois. 1992. Prevalence of Staphylococcus species during the periparturient period in primiparous and multiparous cows. J. Dairy Sci. 75:1835-1839.

Matthews, K. R., R. J. Harmon, and B. A. Smith. 1990. Protective effect of Staphylococcus chromogenes infection against Staphylococcus aureus infection in the lactating bovine mammary gland. J. Dairy Sci. 73:3457-3462.

McInturff, P., W. O. Johnson, D. Cowling, and I. A. Gardner. 2004 Modelling risk when binary outcomes are subject to error. Stat. Med. 23:1095-1109.

Mellmann, A., K. Becker, C. von Eiff, U. Keckevoet, P. Schumann, and D. Harmsen. 2006. Sequencing and staphylococci identification. Emerg. Infect. Dis. 12:333-336.

Mørk, T., H. J. Jorgensen, M. Sunde, B. Kvitle, S. Sviland, S. Waage, and T. Tollersrud. 2012. Persistence of staphylococcal species and genotypes in the bovine udder. Vet. Microbiol. 159:171-180.

Myllys, V. 1995. Staphylococci in heifer mastitis before and after parturition. J. Dairy Res. 62:51-60.

Naushad, S., H. W. Barkema, C. Luby, L. A. Z. Condas, D. A. Carson, D. B. Nobrega, and J. De Buck. 2016. Comprehensive phylogenetic analysis of bovine non-aureus Staphylococcus species based on whole genome sequencing. Front. Microbiol. 7:1990.

Nickerson, S. C. 2009. Control of heifer mastitis: Antimicrobial treatment-An overview. Vet. Microbiol. 134:128-135.

Olde Riekerink, R. G. M., H. W. Barkema, D. F. Kelton, and D. T. Scholl. 2008. Incidence rate of clinical mastitis on Canadian dairy farms. J. Dairy Sci. 91:1366-1377.

Olde Riekerink, R. G., H. W. Barkema, S. Veenstra, D. E. Poole, R. T. Dingwell, and G. P. Keefe. 2006. Prevalence of contagious mastitis pathogens in bulk tank milk in Prince Edward Island. Can. Vet. J. 47:567-572.

Oliver, S. P., and B. M. Jayarao. 1997. Coagulase-negative staphylococcal intramammary infections in cows and heifers during the nonlactating and periparturient periods. J. Vet. Med. B 44:355363.

Osterås, O., L. Sølverød, and O. Reksen. 2006. Milk culture results in a large Norwegian survey - Effects of season, parity, days in milk, resistance, and clustering. J. Dairy Sci. 89:1010-1023.

Piccart, K., J. Verbeke, A. De Visscher, S. Piepers, F. Haesebrouck, and S. De Vliegher. 2016. Local host response following an intramammary challenge with Staphylococcus fleurettii and different strains of Staphylococcus chromogenes in dairy heifers. Vet. Res. 47:56.

Piepers, S., L. De Meulemeester, A. de Kruif, G. Opsomer, H. W. Barkema, and S. De Vliegher. 2007. Prevalence and distribution of mastitis pathogens in subclinically infected dairy cows in Flanders, Belgium. J. Dairy Res. 74:478-483.

Piepers, S., S. De Vliegher, A. de Kruif, G. Opsomer, and H. W. Barkema. 2009. Impact of intramammary infections in dairy heifers on future udder health, milk production, and culling. Vet. Microbiol. 134:113-120.

Piepers, S., G. Opsomer, H. W. Barkema, A. de Kruif, and S. De Vliegher. 2010. Heifers infected with coagulase-negative staphylococci in early lactation have fewer cases of clinical mastitis and higher milk production in their first lactation than noninfected heifers. J. Dairy Sci. 93:2014-2024.

Piepers, S., K. Peeters, G. Opsomer, H. W. Barkema, K. Frankena, and S. De Vliegher. 2011. Pathogen group specific risk factors at herd, heifer and quarter levels for intramammary infections in early lactating dairy heifers. Prev. Vet. Med. 99:91-101.

Piepers, S., Y. H. Schukken, P. Passchyn, and S. De Vliegher. 2013. The effect of intramammary infection with coagulase-negative staphylococci in early lactating heifers on milk yield throughout first lactation revisited. J. Dairy Sci. 96:5095-5105.

Piessens, V., S. De Vliegher, B. Verbist, G. Braem, A. Van Nuffel, L. De Vuyst, M. Heyndrickx, and E. Van Coillie. 2012. Intra-species diversity and epidemiology varies among coagulase-negative 
Staphylococcus species causing bovine intramammary infections. Vet. Microbiol. 155:62-71.

Piessens, V., E. Van Coillie, B. Verbist, K. Supré, G. Braem, A. Van Nuffel, L. De Vuyst, M. Heyndrickx, and S. De Vliegher. 2011. Distribution of coagulase-negative Staphylococcus species from milk and environment of dairy cows differs between herds. J. Dairy Sci. 94:2933-2944.

Pitkälä, A., M. Haveri, S. Pyörälä, V. Myllys, and T. Honkanen-Buzalski. 2004. Bovine mastitis in Finland 2001-Prevalence, distribution of bacteria, and antimicrobial resistance. J. Dairy Sci. $87: 2433-2441$

Pyörälä, S., and S. Taponen. 2009. Coagulase-negative staphylococciemerging mastitis pathogens. Vet. Microbiol. 134:3-8.

Rainard, P., M. Ducelliez, and B. Poutrel. 1990. The contribution of mammary infections by coagulase-negative staphylococci to the herd bulk milk somatic cell count. Vet. Res. Commun. 14:193-198.

Reksen, O., Y. T. Gröhn, J. W. Barlow, and Y. H. Schukken. 2012. Transmission dynamics of intramammary infections with coagulase-negative staphylococci. J. Dairy Sci. 95:4899-4910.

Reyher, K. K., I. R. Dohoo, and C. A. Muckle. 2013. Evaluation of clustering of new intramammary infections in the bovine udder, including the impact of previous infections, herd prevalence, and somatic cell count on their development. J. Dairy Sci. 96:219-233.

Reyher, K. K., S. Dufour, H. W. Barkema, L. Des Coteaux, T. J. Devries, I. R. Dohoo, G. P. Keefe, J. P. Roy, and D. T. Scholl. 2011. The National Cohort of Dairy Farms - A data collection platform for mastitis research in Canada. J. Dairy Sci. 94:1616-1626.

Sampimon, O. C., H. W. Barkema, I. M. G. A. Berends, J. Sol, and T. J. G. M. Lam. 2009a. Prevalence and herd-level risk factors for intramammary infection with coagulase-negative staphylococci in Dutch dairy herds. Vet. Microbiol. 134:37-44.

Sampimon, O. C., R. N. Zadoks, S. De Vliegher, K. Supré, F. Haesebrouck, H. W. Barkema, J. Sol, and T. J. Lam. 2009b. Performance of API Staph ID 32 and Staph-Zym for identification of coagulasenegative staphylococci isolated from bovine milk samples. Vet. Microbiol. 136:300-305.

Schukken, Y. H., R. N. González, L. L. Tikofsky, H. F. Schulte, C. G. Santisteban, F. L. Welcome, G. J. Bennett, M. J. Zurakowski, and R. N. Zadoks. 2009. CNS mastitis: Nothing to worry about? Vet. Microbiol. 134:9-14.

Supré, K., F. Haesebrouck, R. N. Zadoks, M. Vaneechoutte, S. Piepers, and S. De Vliegher. 2011. Some coagulase-negative Staphylococcus species affect udder health more than others. J. Dairy Sci. 94:2329-2340.

Taponen, S., J. Bjorkroth, and S. Pyorala. 2008. Coagulase-negative staphylococci isolated from bovine extramammary sites and intramammary infections in a single dairy herd. J. Dairy Res. 75:422429.

Taponen, S., J. Koort, J. Bjorkroth, H. Saloniemi, and S. Pyorala. 2007. Bovine intramammary infections caused by coagulase-negative staphylococci may persist throughout lactation according to amplified fragment length polymorphism-based analysis. J. Dairy Sci. 90:3301-3307.

Taponen, S., and S. Pyörälä. 2009. Coagulase-negative staphylococci as cause of bovine mastitis-Not so different from Staphylococcus aureus? Vet. Microbiol. 134:29-36.
Taponen, S., H. Simojoki, M. Haveri, H. D. Larsen, and S. Pyörälä 2006. Clinical characteristics and persistence of bovine mastitis caused by different species of coagulase-negative staphylococci identified with API or AFLP. Vet. Microbiol. 115:199-207.

Taponen, S., K. Supre, V. Piessens, E. Van Coillie, S. De Vliegher, and J. M. Koort. 2012. Staphylococcus agnetis sp. nov., a coagulasevariable species from bovine subclinical and mild clinical mastitis. Int. J. Syst. Evol. Microbiol. 62:61-65.

ten Napel, J., Y. de Haas, G. de Jong, T. J. Lam, W. Ouweltjes, and J. J. Windig. 2009. Characterization of distributions of somatic cell counts. J. Dairy Sci. 92:1253-1264.

Tenhagen, B. A., G. Köster, J. Wallmann, and W. Heuwieser. 2006. Prevalence of mastitis pathogens and their resistance against antimicrobial agents in dairy cows in Brandenburg, Germany. J. Dairy Sci. 89:2542-2551.

Thorberg, B. M., M. L. Danielsson-Tham, U. Emanuelson, and K Persson Waller. 2009. Bovine subclinical mastitis caused by different types of coagulase-negative staphylococci. J. Dairy Sci. 92:4962-4970.

Tomazi, T., J. L. Gonçalves, J. R. Barreiro, M. A. Arcari, and M. V. dos Santos. 2015. Bovine subclinical intramammary infection caused by coagulase-negative staphylococci increases somatic cell count but has no effect on milk yield or composition. J. Dairy Sci. 98:3071-3078.

Trinidad, P., S. C. Nickerson, T. K. Alley, and R. W. Adkinson. 1990 Efficacy of intramammary treatment in unbred and primigravid dairy heifers. J. Am. Vet. Med. Assoc. 197:465-470.

Vanderhaeghen, W., S. Piepers, F. Leroy, E. Van Coillie, F. Haesebrouck, and S. De Vliegher. 2014. Invited review: Effect, persistence, and virulence of coagulase-negative Staphylococcus species associated with ruminant udder health. J. Dairy Sci. 97:5275-5293.

Vanderhaeghen, W., S. Piepers, F. Leroy, E. Van Coillie, F. Haesebrouck, and S. De Vliegher. 2015. Identification, typing, ecology and epidemiology of coagulase negative staphylococci associated with ruminants. Vet. J. 203:44-51.

White, D. G., R. J. Harmon, J. E. Matos, and B. E. Langlois. 1989 Isolation and identification of coagulase-negative Staphylococcus species from bovine body sites and streak canals of nulliparous heifers. J. Dairy Sci. 72:1886-1892.

Woodward, W. D., T. E. Besser, A. C. Ward, and L. B. Corbeil. 1987. In vitro growth inhibition of mastitis pathogens by bovine teat skin normal flora. Can. J. Vet. Res. 51:27-31.

Woodward, W. D., A. C. S. Ward, L. K. Fox, and L. B. Corbeil. 1988. Teat skin normal flora and colonization with mastitis pathogen inhibitors. Vet. Microbiol. 17:357-365.

Zadoks, R. N., H. W. Barkema, O. C. Sampimon, G. J. Wellenberg, Y. T. Gröhn, and Y. H. Schukken. 2001. Cow- and quarter-level risk factors for Streptococcus uberis and Staphylococcus aureus mastitis. J. Dairy Sci. 84:2649-2663.

Zadoks, R. N., J. R. Middleton, S. McDougall, J. Katholm, and Y. H. Schukken. 2011. Molecular epidemiology of mastitis pathogens of dairy cattle and comparative relevance to humans. J. Mammary Gland Biol. Neoplasia 16:357-372.

Zadoks, R. N., and J. L. Watts. 2009. Species identification of coagulase-negative staphylococci: Genotyping is superior to phenotyping. Vet. Microbiol. 134:20-28. 